\title{
Information Processing in the Primate Basal Ganglia during Sensory-Guided and Internally Driven Rhythmic Tapping
}

\author{
Ramón Bartolo, Luis Prado, and Hugo Merchant \\ Instituto de Neurobiología, Universidad Nacional Autónoma de México, Campus Juriquilla, Boulevard Juriquilla 3001, Querétaro, 76230, México
}

Gamma $(\gamma)$ and beta $(\beta)$ oscillations seem to play complementary functions in the cortico-basal ganglia-thalamo-cortical circuit (CBGT) during motor behavior. We investigated the time-varying changes of the putaminal spiking activity and the spectral power of local field potentials (LFPs) during a task where the rhythmic tapping of monkeys was guided by isochronous stimuli separated by a fixed duration (synchronization phase), followed by a period of internally timed movements (continuation phase). We found that the power of both bands and the discharge rate of cells showed an orderly change in magnitude as a function of the duration and/or the serial order of the intervals executed rhythmically. More LFPs were tuned to duration and/or serial order in the $\beta$ - than the $\gamma$-band, although different values of preferred features were represented by single cells and by both bands. Importantly, in the LFPs tuned to serial order, there was a strong bias toward the continuation phase for the $\beta$-band when aligned to movements, and a bias toward the synchronization phase for the $\gamma$-band when aligned to the stimuli. Our results suggest that $\gamma$-oscillations reflect local computations associated with stimulus processing, whereas $\beta$-activity involves the entrainment of large putaminal circuits, probably in conjunction with other elements of CBGT, during internally driven rhythmic tapping.

Key words: interval tuning; rhesus monkey; spikes and LFPs; synchronization-continuation task; timing

\section{Introduction}

Rhythmic activity in the brain is thought to reflect coordinated network activity and to influence single-cell responses during sensory, cognitive, and motor behaviors (Buzsáki, 2006). For example, in the motor system, the oscillatory activity in local field potentials (LFPs) in the beta- $(\beta, 13-30 \mathrm{~Hz})$ and gamma-bands $(\gamma, 30-70 \mathrm{~Hz})$ play a complementary role in the sensorimotor computations involved in the control of voluntary movements. Numerous studies have provided evidence that cortical $\beta$-band oscillations increase after the presentation of a cue that guides a movement, decrease during movement execution, and increase again during holding periods after the movement (Sanes and Donoghue, 1993; Murthy and Fetz, 1996; Baker et al., 1997). In contrast, during the preparation and execution of movements, the $\beta$-band is replaced by $\gamma$-band rhythmic activity (Schoffelen et al., 2005). Furthermore, $\beta$-oscillations emerge with small time delays between areas of the cortico-basal ganglia-thalamo-cortical loop

\footnotetext{
Received June 22, 2013; revised Feb. 3, 2014; accepted Feb. 9, 2014.

Author contributions: H.M. designed research; R.B., L.P., and H.M. performed research; R.B. and H.M. analyzed data; R.B. and H.M. wrote the paper.

This work was supported by Consejo Nacional de Ciencia y Tecnologia Grants 151223, PAPIIT IN200511 to H.M. and Consejo Nacional de Ciencia y Tecnologia scholarship 202421 to R.B. This work is part of the Doctoral Thesis of Ramón Bartolo, Programa de Doctorado en Ciencias Biomédicas, Universidad Nacional Autónoma de México. We thank Raul Paulín and Juan José Ortiz for technical assistance; and David Crowe, Victor de Lafuente, Saskia Haegens, Juan Carlos Méndez, and Ranulfo Romo for fruitful comments on the manuscript.

The authors declare no competing financial interests.

Correspondence should be addressed to Dr. Hugo Merchant, Instituto de Neurobiología, Universidad Nacional Autónoma de México, Campus Juriquilla, Boulevard Juriquilla 3001, Querétaro, 76230, México. E-mail: hugomerchant@unam.mx,merch006@umn.edu.

DOI:10.1523/JNEUROSCI.2679-13.2014

Copyright $\odot 2014$ the authors $\quad 0270-6474 / 14 / 343910-14 \$ 15.00 / 0$
}

(CBGT) and play a distinct role in coordinating sensorimotor information within this circuit (Courtemanche et al., 2003; Howe et al., 2011; Leventhal et al., 2012), whereas $\gamma$-activity is inherently local (Kalenscher et al., 2010; Howe et al., 2011). Therefore, a recent hypothesis suggests that endogenously driven top-down processes are associated with large-scale communication in the $\beta$-band (Engel and Fries, 2010). On the contrary, spikefield synchrony is primarily local during $\gamma$-bursts, and $\gamma$-band increments have been associated with sensory cued bottom-up behaviors in cortical and subcortical areas (Kopell et al., 2000; Berke, 2009; Fries, 2009). Nevertheless, more evidence is needed to test these ideas.

A task that has been a pillar in the interval timing literature, called the synchronization and continuation tapping task (SCT), is ideally situated to investigate the association between sensory versus internally driven behaviors and the $\gamma$ and $\beta$-bands, respectively (Wing and Kristofferson, 1973; Merchant et al., 2008b, 2008c; Zarco et al., 2009; Repp and Su, 2013). This paradigm has an initial period where the rhythmic behavior is synchronized to a metronome of isochronous stimuli in the hundreds of milliseconds range (synchronization phase), followed by a period where subjects internally temporalize their tapping movements (continuation phase). Hence, oscillations in the $\gamma$-band (indicative of local processing) would be expected during the synchronization phase, whereas $\beta$-band oscillations (global processing) would be expected during the continuation phase of the SCT. Indeed, brain oscillatory activity has been suggested as a major signal to encode the passage of time (Treisman et al., 1994). Recent imaging and neurophysiological studies have implicated the CBGT as a fundamental part of the timing mechanism in time 
A

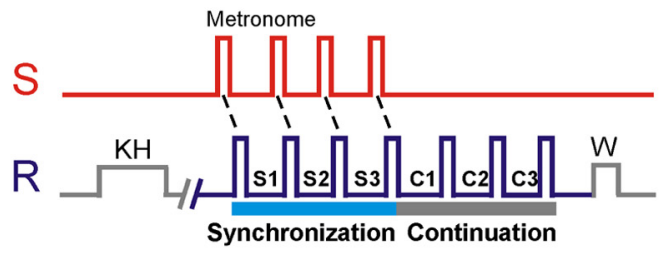

B

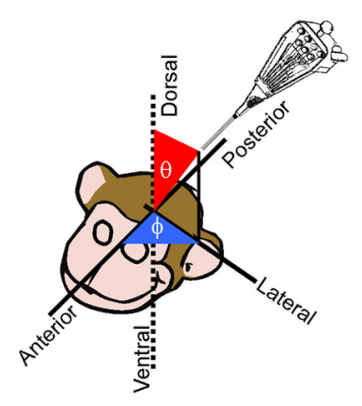

C

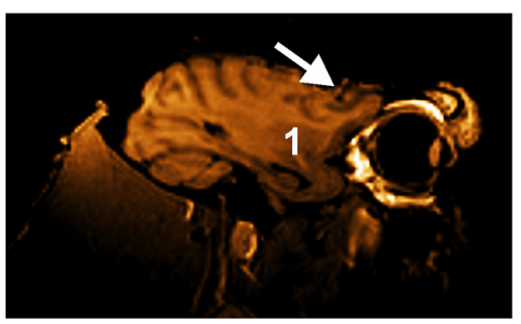

D

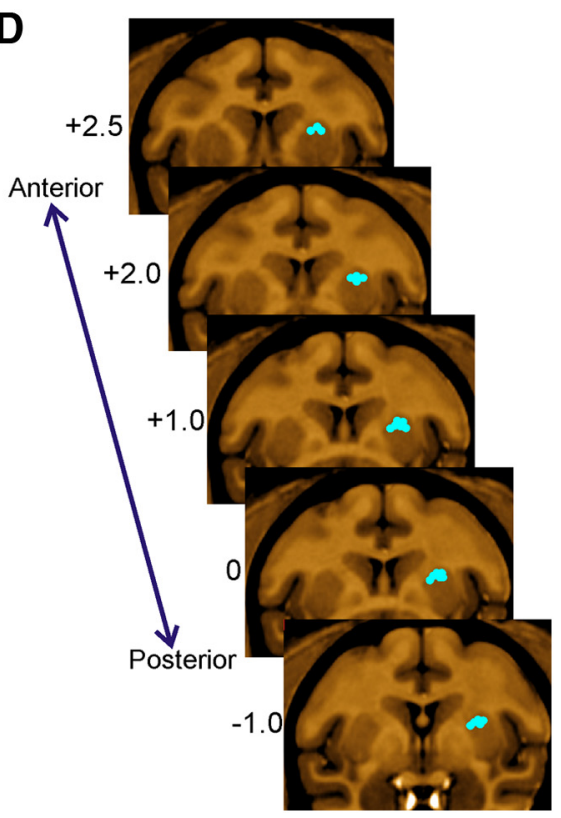

Figure 1. SCT and location of recording sites. $A$, Sensory and motor events in the SCT. S, Stimuli with an isochronous interval; $R$, push-button press; KH, key hold; W, reward; S1-S3, intertap intervals of the synchronization phase; C1-C3, intervals of the continuation phase. $\boldsymbol{B}$, Navigation method to reach the dorsal putamen. Guiding cannulae were oriented in spherical coordinates with respect to the anterior-posterior, medial-lateral, and dorsal-ventral axes of the monkey's head. MRI was used to calculate the appropriate coordinates and to verify the trajectory. $\mathbf{C}$, MRI in the parasagittal plane where the white arrow points to the trajectory of an MRI-compatible cannula and the number 1 is located on the putamen. $\boldsymbol{D}$, Representative standard coronal sections of the macaque brain (Frey et al., 2011) illustrating the area in which LFPs were recorded for one monkey. The numbers to the left are millimeters with respect to the anterior commissure. Blue dots correspond to the recording sites.

perception (Macar et al., 2006; Harrington et al., 2010) and time production tasks in the scale of hundreds of milliseconds (Jin et al., 2009; Wiener et al., 2010), including the SCT (Rao et al., 1997; Merchant et al., 2011, 2013a; Perez et al., 2013). Therefore, in the present study, we investigated the dynamic changes of both the spiking responses and the $\gamma$ - and $\beta$-activity in LFPs of the putamen during a version of SCT with three intervals in the synchronization phase and three intervals in the continuation phase.

\section{Materials and Methods}

\section{General}

Two male monkeys (Macaca mulatta, 5-7 kg body weight) were trained to tap on a push button in a SCT (see below). Neurophysiological recordings were performed in the putamen during performance of the task (Merchant et al., 1997). All the animal experimental procedures were approved by the National University of Mexico Institutional Animal Care and Use Committee and conformed to the principles outlined in the Guide for Care and Use of Laboratory Animals (National Institutes of Health, publication number $85-23$, revised 1985).

Task (SCT)

The SCT used in this study has been described previously (Zarco et al., 2009; Merchant et al., 2011). Briefly, the monkeys were required to push a button each time stimuli with a constant interstimulus interval were presented, which resulted in a stimulus-movement cycle (see Fig. 1A). After four consecutive synchronized movements, the stimuli were eliminated, and the monkeys continued tapping with the same interval for three additional intervals, producing 6 sequential intertap intervals. Liquid reward contingencies changed as a function of the trial duration, as described previously (Zarco et al., 2009). Trials were separated by a variable intertrial interval (2-4 s). Trials with produced intervals $<18 \%$ of absolute error with respect to the target interval were considered correct. The target intertap intervals, defined by brief auditory $(33 \mathrm{~ms}, 2000 \mathrm{~Hz}, 65 \mathrm{~dB})$ or visual ( $32 \mathrm{~ms}, 10 \times 10 \mathrm{~cm}$ square) stimuli were 450 , $550,650,850$, and $1000 \mathrm{~ms}$ and were presented in random order within a repetition. Five repetitions were collected for each target interval.

\section{Neural recordings}

LFPs and single-cell activity were recorded in the putamen using a system with 7 independently movable microelectrodes (1-3 $\mathrm{m} \Omega$, Thomas Recording) (Merchant et al., 2001). Electrodes were placed using guiding cannulae. Recordings were made in sites where single-unit activity was found, and the recording sites changed from session to session. At each site, raw extracellular electric activity was sampled at $40 \mathrm{kHz}$. Spikes were manually sorted using the Offline Sorter (Plexon). LFPs were acquired by low-pass filtering the raw signal (Thomas Recording, cutoff $140 \mathrm{~Hz}$ ) and then down-sampling the filtered signal at $571 \mathrm{~Hz}$. Structural MRI was used to localize the recording sites. Using the voxel size, the 3D Cartesian coordinates $(x, y, z)$ of the insertion site (origin), and the target recording site, we computed the following three measures in spherical coordinates (see Fig. 1B):

$\rho$

$$
\begin{gathered}
=\sqrt{\left(x_{\text {target }}-x_{\text {origin }}\right)^{2}+\left(y_{\text {target }}-y_{\text {origin }}()^{2}\right)+\left(z_{\text {target }}-z_{\text {origin }}\right)^{2}} \\
\theta=\arctan \left(\frac{y_{\text {target }}-y_{\text {origin }}}{x_{\text {target }}-x_{\text {origin }}}\right) \\
\phi=\arccos \left(\frac{z_{\text {target }}-z_{\text {origin }}}{\rho}\right)
\end{gathered}
$$

With this information, we determined the appropriate insertion angles $\phi$ (rotation), $\theta$ (inclination), and the distance $\rho$ that the electrodes will move forward from the insertion site to reach the recording target area. The insertion angles were verified using an MRI-compatible cannula at $\phi$ and $\theta$ in an additional MR scan (see Fig. 1C). Thus, the electrodes were moved to the dorsal portion of the putamen using these insertion angles. Electrophysiological recordings were performed from the putamen contralateral to the moving hand, at an anteroposterior level within $2.75 \mathrm{~mm}$ and $-1.0 \mathrm{~mm}$ referred to the anterior commissure (see Fig. 1D). Remarkably, during the recording sessions the actual distance at which we found striatal activity was similar to the predicted distance $\rho$.

\section{Data analysis}

General. Subroutines written in MATLAB (version 7.6.0.324, MathWorks) were used for all the analyses. LFP signals were aligned to each tap or stimulus in the task to look for associated power modulations. Power modulations were quantified and further analyzed.

Spectral analysis. Spectral quantities were estimated using the multitaper method (Thomson, 1982) implemented in Chronux 2.00 (Mitra and Bokil, 2008). The bandwidth used for smoothing was always $10 \mathrm{~Hz}$. 

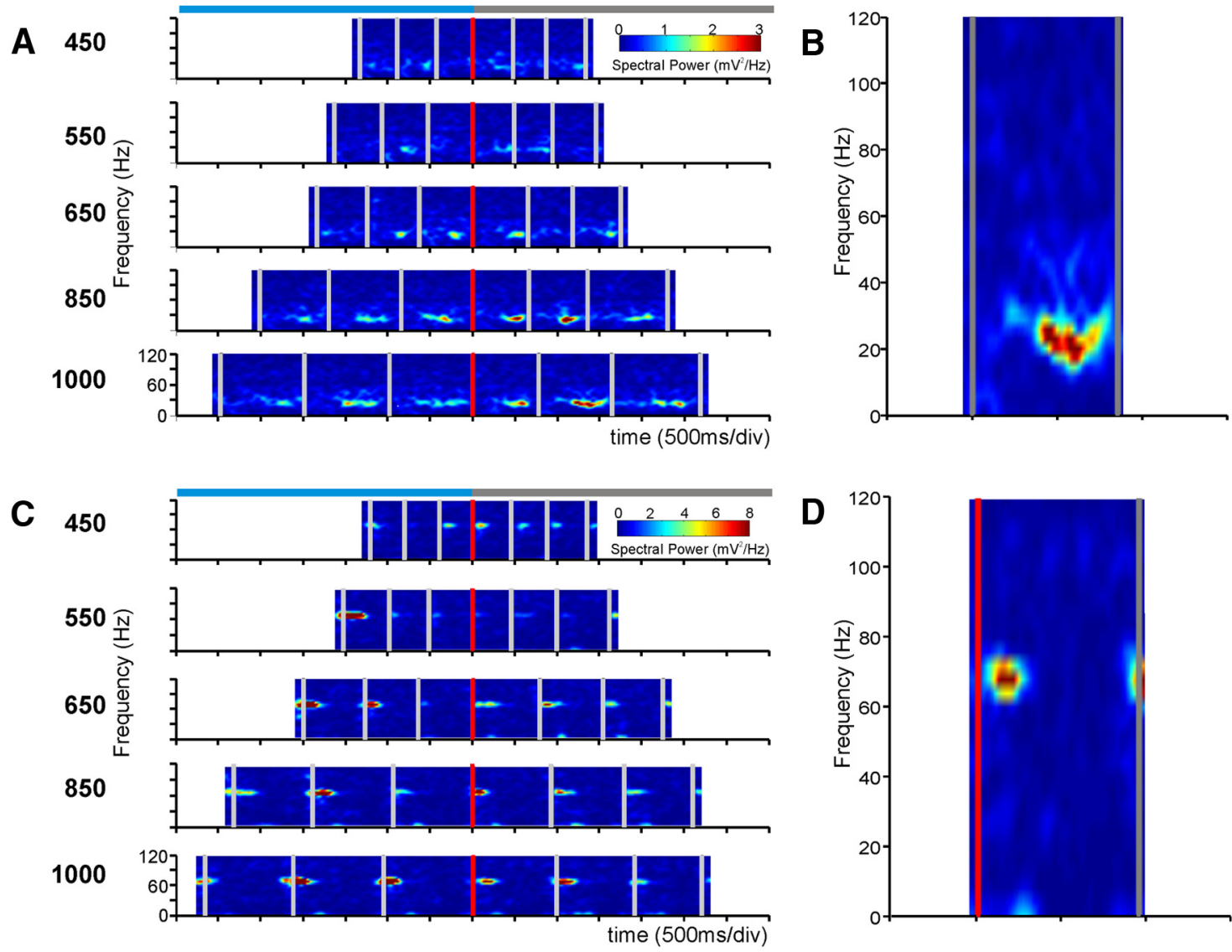

Figure 2. Transient increases in the spectral power of LFPs. A, Raw, unsmoothed spectrograms of a single LFP recording. Each plot corresponds to the target interval indicated on the left. The vertical axis is the frequency of the oscillatory activity, and the horizontal axis is the time during the performance of the task. Gray vertical bars represent the times at which the monkey tapped on the push-button. All the spectrograms are aligned to the last tap of the synchronization phase (red vertical bar). Top, Light-blue and gray horizontal bars represent the synchronization and continuation phases, respectively. Each spectrogram is the average of 5 trials. $\boldsymbol{B}$, Close-up of the $(2$ intertap interval of the $1000 \mathrm{~ms}$ plot in $\boldsymbol{A}$, showing that transient power increases occurred in the $\beta$-band. C, Spectrograms of a different LFP recording showing transient power increases in a larger frequency than in $A . D$, Close-up of the C1 intertap interval of the $1000 \mathrm{~ms}$ plot in C showing that the transient power increments occurred in the $\gamma$-band.

Spectrograms were constructed for each trial using a sliding window, with steps of $10 \mathrm{~ms}$, covering the whole LFP time-series. For frequencies in the $\beta$-band $(10-30 \mathrm{~Hz})$, the window size was $300 \mathrm{~ms}$ and 1 Slepian taper was used. Noteworthy, we also tested Hanning and Hamming tapers for this band, obtaining similar results. For frequencies in the $\gamma$-band $(30-80 \mathrm{~Hz})$, the window size was $200 \mathrm{~ms}$ and 3 Slepian tapers were used. Spectral density estimates were expressed as $z$-scores with respect to the mean and SD of all the recording session. Behavioral variability produced intertap intervals that varied across trials (e.g., the produced duration of element S2 of a given target can vary across the 5 trials); hence, to obtain trial-averaged spectrograms we aligned signal segments of each intertap interval, giving 5 segments of different lengths. To get equal-length segments, the middle-length segment was used as a reference, and the segments from the remaining 4 trials were trimmed or zero-padded accordingly; averaged spectral estimates were computed from these aligned segments for displaying purposes only.

The time-varying modulation of spectral estimates was assessed on the curves of integrated (trapezoidal) $z$-score values within the $\beta$ - or $\gamma$-bands. Significant modulations were defined as the changes in integrated spectral density that were above a threshold (session mean $+\mathrm{SD}$ ) for at least $50 \mathrm{~ms}$ in at least 3 trials.

Classification of spectral modulation patterns. LFP $\beta$ - and $\gamma$-band power curves with significant Friedman effects on serial order were segregated in two functionally distinct categories, namely, ordinal- or phase-selective curves, using K-means clustering. This procedure partitioned LFPs into 13 clusters, where each curve was associated to the cluster with the nearest mean (Johnson and Wichern, 1998). The initial means of the clusters were as follows: $\mu_{1}=(1,0,0,0,0,0) ; \mu_{2}=$
$(0,1,0,0,0,0) ; \mu_{3}=(0,0,1,0,0,0) ; \mu_{4}=(0,0,0,1,0,0) ; \mu_{5}=(0,0,0,0,1,0) ;$ $\mu_{6}=(0,0,0,0,0,1) ; \mu_{7}=(1,1,0,0,0,0) ; \mu_{8}=(0,1,1,0,0,0) ; \mu_{9}=$ $(0,0,1,1,0,0) ; \mu_{10}=(0,0,0,1,1,0) ; \mu_{11}=(0,0,0,0,1,1) ; \mu_{12}=(1,1,1,0,0,0)$; and $\mu_{13}=(0,0,0,1,1,1)$.

where $\mu_{1}-\mu_{6}$ correspond to the clusters that responded only to one element of the six interval sequence, $\mu_{7}-\mu_{11}$ to the clusters that responded to two consecutive elements of the sequence, and $\mu_{12}$ and $\mu_{13}$ to the synchronization and continuation phase, respectively. The normalized integrated power for each ordinal element, across interval durations and trials (a total of 30 trials for each ordinal element) was used as the dependent variable. A one-way multivariate ANOVA was performed using the normalized responses of cells across each ordinal element as dependent variables and the clustering results as factors. The results showed that the 13 clusters were significantly different for each other $\left(\beta\right.$-auditory $\chi_{(84)}^{2}=1.25 \times 10^{3} ; \beta$-visual $\chi_{(84)}^{2}=1.24 \times 10^{3}$; $\gamma$-auditory $\chi_{(78)}^{2}=949.59 ; \gamma$-visual $\chi_{(78)}^{2}=802.71 ; p<0.00001$ for all conditions).

Interval and serial-order tuning. The Friedman test was used to identify recordings with a significant effect of interval duration or serial order on the magnitude of the spectral modulation. A Gaussian function was fitted to the integrated power to determine the tuning to interval duration or serial order only for recordings with a significant effect revealed by the Friedman test. The integrated power for each produced interval during the SCT was treated as the dependent variable in a 
A

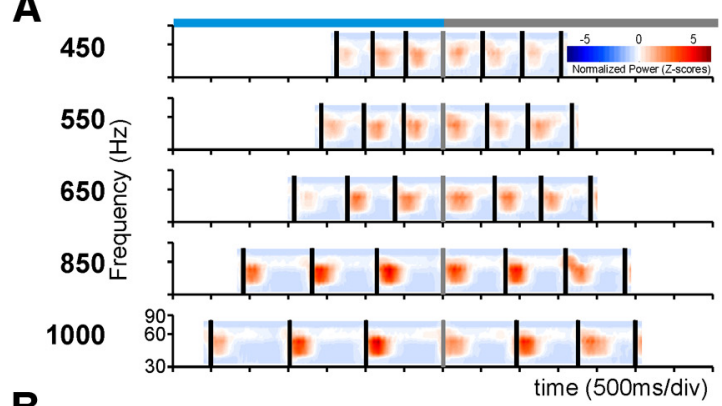

B

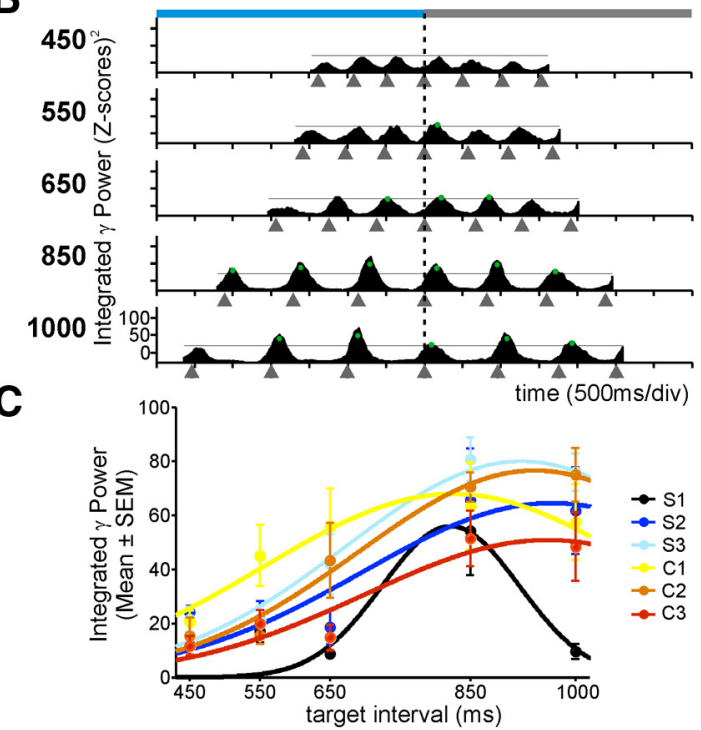

D
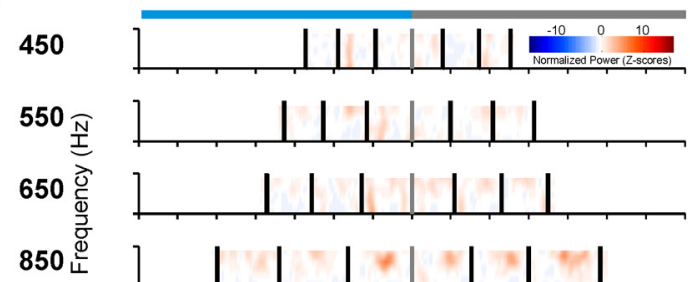

1000

E

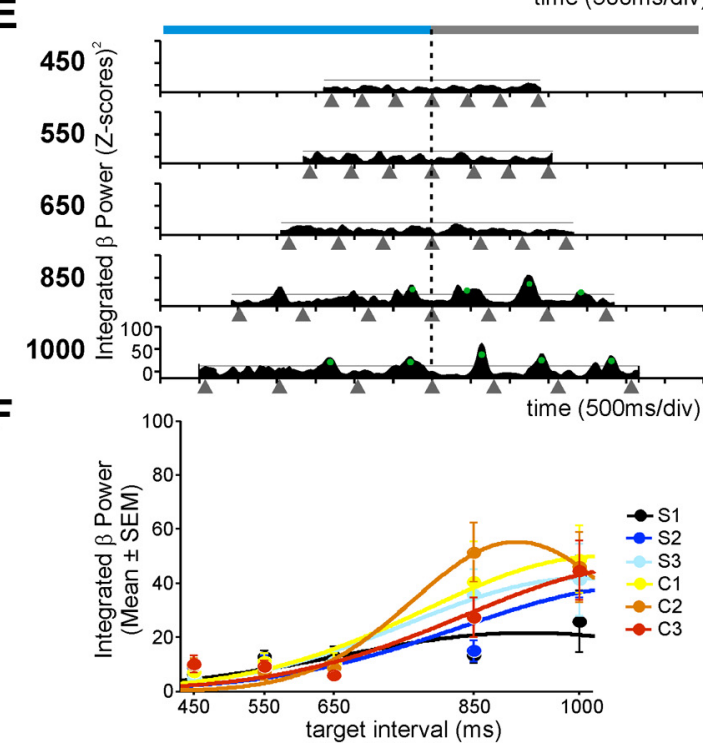

Figure 3. Time-varying modulations in the $\gamma$ - and $\beta$-power of two different LFP signals that show selectivity to interval duration. $A$, Normalized spectrograms in the $\gamma$-band. Each plot corresponds to the target interval indicated on the left. The horizontal axis is the time during the performance of the task. Black vertical bars represent the times at which the monkey tapped on the push-button. All the spectrograms are aligned to the last tap of the synchronization phase (gray vertical bar). Top, Light-blue and gray horizontal bars represent the synchronization and continuation phases, respectively. $\boldsymbol{B}$, Plots of the integrated power time-series for each target duration. Gray triangles below the time axis represent tap times. Green dots correspond to power modulations above the 1 SD threshold (black solid line) for a minimum of $50 \mathrm{~ms}$ across trials. The vertical dotted line indicates the last tap of the synchronization phase. $\boldsymbol{C}$, Interval tuning in the integrated $\gamma$ power. Dots are the mean \pm SEM, and lines indicate the fitted Gaussian functions. Tuning functions were calculated for each of the six elements of the task sequence (S1-S3 for synchronization and C1-C3 for continuation) and are color-coded (inset). $\mathbf{D}-\boldsymbol{F}$, Same as in $\boldsymbol{A}-\boldsymbol{C}$ for a different LFP recording that showed $\beta$-band power modulations that were selective for interval duration.

nonlinear regression where the interval duration or serial order was used as independent variables in the following equation:

$$
f(s)=h e^{-\left(\frac{\left\|s, s_{p}\right\|}{k}\right)^{2}}
$$

where $f(s)$ corresponds to the integrated power associated to a particular value of the independent variable $s, h$ is the parameter of maximum height, and $\kappa$ is the parameter of dispersion. $\left\|s, s_{p}\right\|$ is the Euclidean distance between $s$ and $s_{p}$, where $s_{p}$ corresponds to the preferred interval or preferred serial order. The regression was performed for each produced interval in the SCT sequence for the interval duration fittings, as well as for each duration for the serial order fittings. The function was fitted using the least-squares method following a genetic algorithm (Kuri-Morales, 2004). A detailed analysis of the residuals was performed (Draper and Smith, 1981) and the $R^{2}$ calculated. The statistical significance of the fittings was assessed using the corresponding ANOVA for the regression.

Tuning dispersion measure. We used the half -width dispersion, $\kappa_{50}$, at the midpoint of the tuning magnitude as the consistent measure of tuning dispersion. The corresponding equation was as follows:

$$
k_{50}=\sqrt{\ln 2 k}
$$

Coherence analysis. Simultaneously recorded, raw LFP signals from serial order tuned recordings were used for coherence analysis with the purpose of determining the local or global nature of the oscillatory entrain- ment inside the putamen. We used the segments covering intervals C1-C2 to compute the $\beta$-band coherence, and segments S2-C1 for the $\gamma$-band coherence, based on the distributions of preferred serial order showed in Figure 9. Two and three Slepian tapers were used to estimate the $\beta$ - and $\gamma$-band spectra, respectively, using the multitaper method implemented in Chronux 2.00 (Mitra and Bokil, 2008). Coherence was calculated according to the relation as follows:

$$
C_{i \cdot j}=\frac{S_{i \cdot j}}{\sqrt{S_{i} S_{j}}}
$$

Where $C_{i \cdot j}$ is the complex coherence, $S_{i}$ and $S_{j}$ are the spectra of the LFPs in channels $i$ and $j$, respectively, and $S_{i \cdot \cdot}$ is the cross-spectrum of the two signals. The complex coherence within the frequency band of interest was averaged across trials and durations. This average was used to calculate magnitude and phase. The coherence magnitude is defined as $a b s\left(C_{i \cdot j}\right)$, and the phase-angle was given by the absolute value of $\operatorname{atan} 2\left(i m a g\left(C_{i \cdot j}\right), \operatorname{real}\left(C_{i \cdot j}\right)\right)$.

Spike-field phase locking analysis. Raw LFP signals were zero-phase bandpass filtered ( $\beta$ or $\gamma$ ). The filtered signal was then normalized to $z$-scores with respect to the session mean and SD. Then simultaneously recorded single-unit activity from the same site was aligned to the LFP and behavioral tap times. Units that reached a spike rate $>5 \mathrm{~Hz}$ were used for phase-locking analysis. We used the Hilbert transform of the normalized LFP to calculate the instantaneous phase and the envelope. Bursts of $\beta$ - or $\gamma$-activity were defined as the periods where the envelope of the 
Table 1. Number of LFPs with significant effects on Friedman test $(p<0.05)$ for the noted factors, from a total of 285 recording sites ${ }^{a}$

\begin{tabular}{lccccc}
\hline & $\beta$ & & & $\gamma$ & \\
\cline { 2 - 3 } \cline { 6 - 6 } & Auditory & Visual & & Auditory & Visual \\
\hline Duration & 56 & 53 & 64 & 74 \\
Serial order & 48 & 51 & & 44 & 44 \\
Duration and serial order & 120 & 130 & & 106 & 94 \\
Sensorimotor & 8 & 9 & & 16 & 16 \\
No effect & 53 & 42 & & 55 & 57 \\
Total & 285 & 285 & & 285 & 285 \\
\hline
\end{tabular}

${ }^{a}$ LFPs with sensorimotor responses showed similar power modulations across duration and serial order $\left(\chi^{2}\right.$ test, $p>0.05$ ).

signal was maintained above a $z$-score threshold of 1.96 for at least 3 oscillation cycles (Howe et al., 2011). The phases of spikes that occurred $100 \mathrm{~ms}$ around the peak of the burst were analyzed. By convention, the peak of an oscillation was set to $90^{\circ}$ of phase angle. Circular statistics were performed using the CircStat toolbox (Berens, 2009). We determined whether the spikes were significantly phase-locked during bursts using the Rayleigh test (Batschelet, 1981). Population analyses (mean resultant vector length and phase angle) were based on the circular mean of significantly phase-locked individual neurons.

\section{Results}

Interval tuning in the putaminal spectral modulations

Two monkeys (M. mulatta) were trained in an SCT where animals tapped on a push-button to produce a sequence of three intertap intervals guided by isochronous stimuli, followed by three intertap intervals without sensory guidance. Thus, the SCT has a sensory-guided phase called synchronization and an internally driven phase called continuation (Fig. 1A; see Materials and Methods). Brief auditory or visual interval markers were used to guide behavior during the synchronization phase and 5 target intervals were used ranging from 450 to $1000 \mathrm{~ms}$. Once the animals reached a performance of $>75 \%$ of correct trials, LFPs and single-unit recordings were performed in the dorsal putamen during task performance (Fig. $1 B-D$ ). Comprehensive analyses of the monkeys' behavior were described previously (Zarco et al., 2009; Merchant et al., 2013b). Briefly, the monkeys underestimated the intervals by $\sim 35 \mathrm{~ms}$ across target intervals, and their temporal variability followed the scalar property of interval timing (Gibbon et al., 1997; Merchant et al., 2008c; Donnet et al., submitted), namely, they showed a linear increase in the variability of the produced intervals as a function of the interval duration.

The multitaper Fourier transform was performed to obtain spectral power estimates of LFPs aligned to the tap movements during the execution of the SCT (see Materials and Methods). Detailed analyses of the spectrograms performed for frequencies ranging from 5 to $120 \mathrm{~Hz}$ revealed clear time-varying modulations in power for the $\beta-(10-30 \mathrm{~Hz})$ and $\gamma-(30-80 \mathrm{~Hz})$ bands (Fig. 2). Figure $3 A-C$ shows an example from a single recording site in which the LFP showed transient bursts of increased power in the $\gamma$-band after each button-press for all durations. Across recordings, the mean duration for transient, high amplitude bursts during task performance was 159.3 and $159.5 \mathrm{~ms}$ for the $\beta$ and $\gamma$-bands, respectively. Interestingly, the high amplitude bursts in the example of Figure 3 also showed a larger power modulation for longer interval durations, and this was more evident when the power $z$-scores were integrated across frequencies, as depicted in Figure $3 B$. Overall, a large proportion of recording sites showed a significant effect of interval duration on the integrated power (Friedman test; Table 1). Indeed, when the integrated power of Figure $3 B$ was plotted as a function of interval duration, a clear interval tuning was observed in the LFP oscilla-

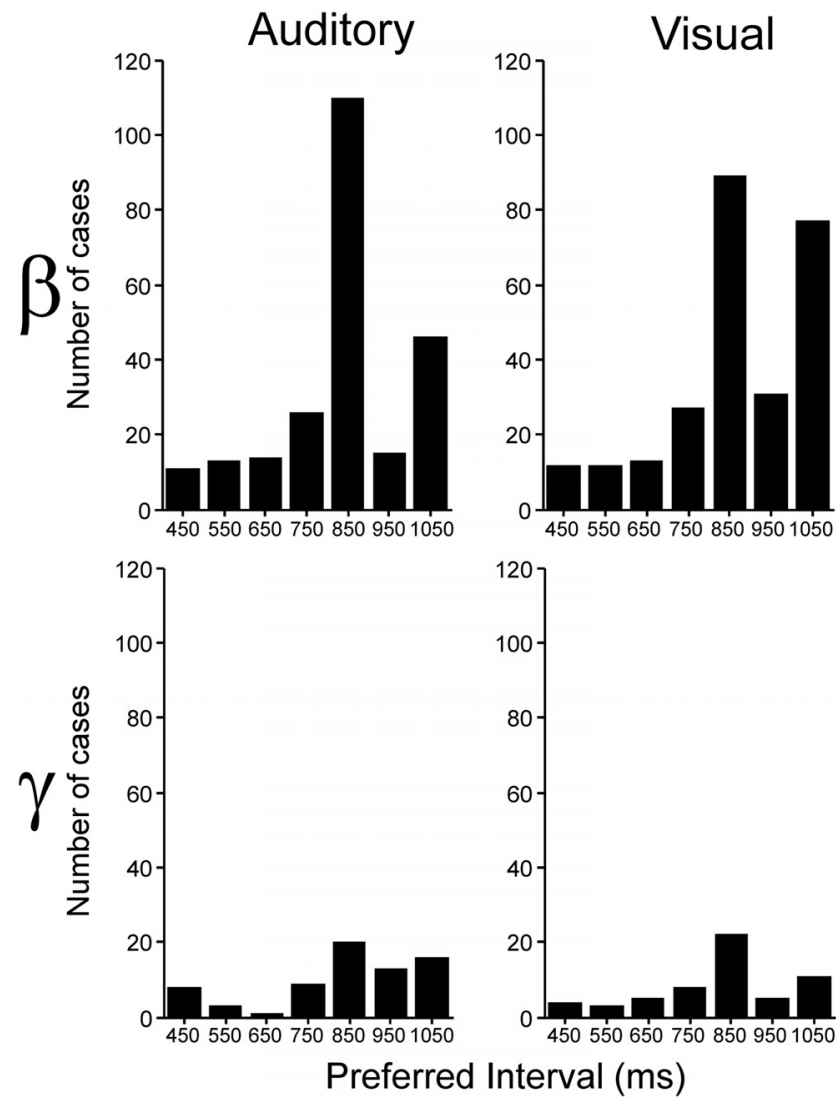

Figure 4. Distribution of preferred interval durations separated by frequency band ( $\beta$ or $\gamma$ ) and modality (auditory or visual).

tory activity, and Gaussian function fittings revealed that the $\gamma$-band power showed preferred intervals $\sim 900 \mathrm{~ms}$ across the six elements of the SCT sequence (Fig. $3 C$ ). Interval tuning was also observed in the $\beta$-band (Fig. 3D-F).

At the population level, the distributions of preferred intervals showed a bias toward intervals $\sim 850 \mathrm{~ms}$ in both frequency bands and for both interval marker modalities (see Table 3; Fig. 4; medians $A \beta, 822.6 ; \mathrm{V} \beta, 822.1 ; \mathrm{A} \gamma, 819.7 ; \mathrm{V} \gamma, 822)$. It is evident in Figure 4 that more recording sites were tuned in the $\beta$ - than the $\gamma$-band, although in both cases there is a wide range of preferred intervals represented in the putamen. Therefore, these results suggest that the putamen contains a representation of interval duration, where different local cell populations oscillate in the $\beta$ - or $\gamma$-bands for specific intervals during the SCT.

Duration and serial-order selectivity of spectral modulations Figure 5 shows the spectrograms (Fig. 5A) and the time series of the integrated power (Fig. $5 B$ ) for the $\beta$-band of an LFP recording that was tuned for longer interval durations. In addition, this LFP showed an orderly change in the power for the serial order of the SCT, with a peak in oscillatory activity during the first two elements of the continuation phase of the SCT, describing a tuning curve. Figure $5 C$ shows a different LFP where the $\gamma$-band was simultaneously tuned to longer durations and to the synchronization phase. Indeed, the oscillatory activity of a large proportion of LFPs of the putamen in the $\beta$ - and $\gamma$-bands showed simultaneous selectivity to interval duration and serial order. Table 1 indicates that a large number of the recording sites showed significant effects of duration and serial order in both frequency 
A 450

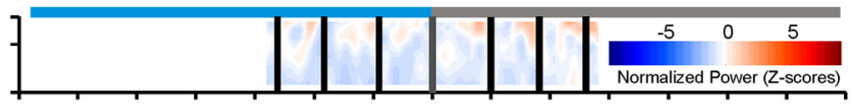

550

650

850

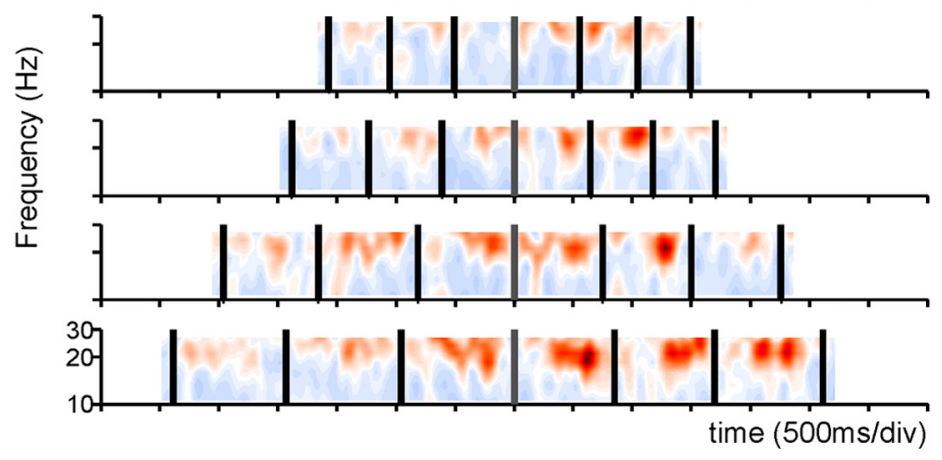

B

450

550

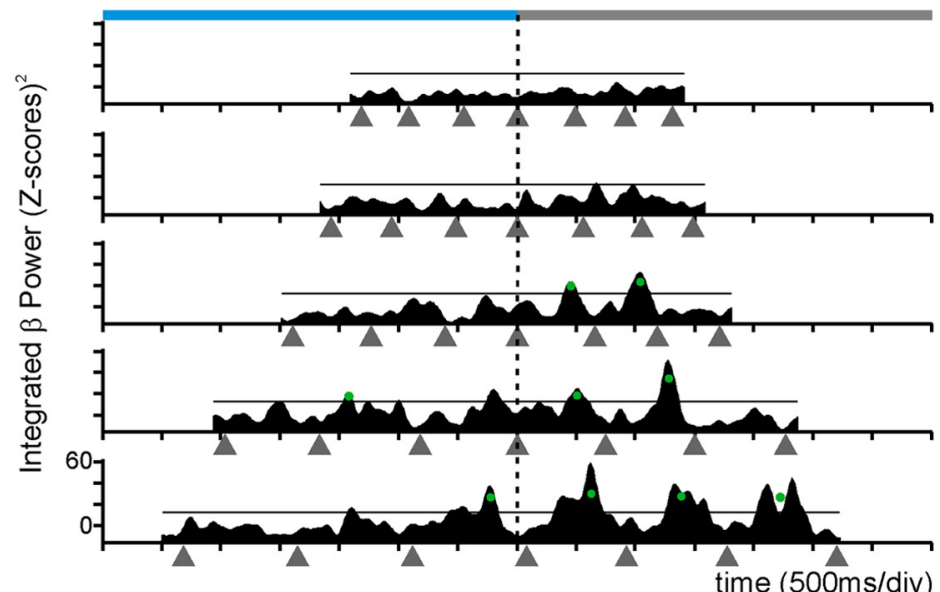

C

450

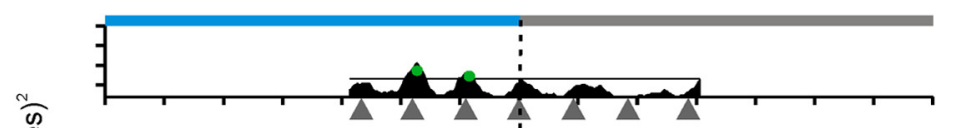

550

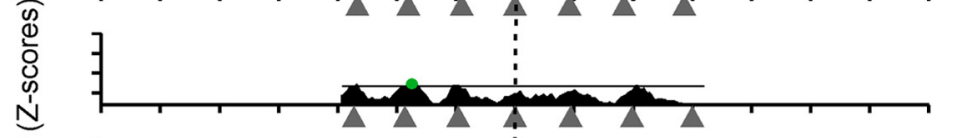

650

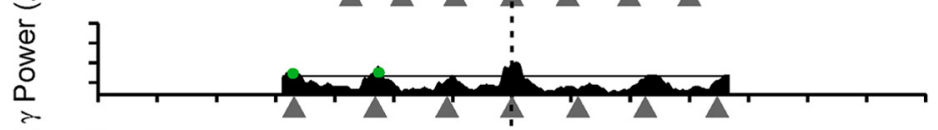

850

1000

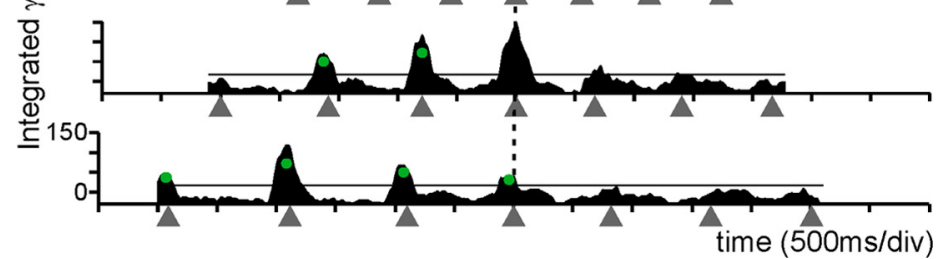

Figure 5. Dual selectivity to the interval duration and the task phase in the LFP $\beta$ power. $\boldsymbol{A}, \boldsymbol{\beta}$-Band spectrogram of an LFP recording with power increments during the continuation phase of long interval durations. $\boldsymbol{B}$, Integrated power of the $\beta$-band for the spectrogram in $\boldsymbol{A}$. $\boldsymbol{C}$, Integrated power of the $\gamma$-band of another LFP with larger oscillatory activity for longer durations during the synchronization phase in the visual condition. The same conventions as in Figure 3.

bands (Friedman tests, $p<0.05$ ). In contrast, there was a small number of nonselective LFPs with power modulations of similar magnitude across the six elements of the SCT sequence and all durations and were classified as sensorimotor responses (Table 1; Fig. 6). Collectively, these findings provide evidence for the coexistence of neural signals associated with the organization of sequential motor behavior and the produced duration during the SCT in the putamen (Figs. 4 and 5). Below we describe how the tuning for interval and serial order in putaminal cells is related with the tuning of the oscillatory activity in the LFPs for these parameters of the task.
Sequential selectivity in the oscillatory activity

The magnitude of the integrated power in LFPs with significant effects of serial order (Friedman tests, $p<0.05$ ) was segregated in two functionally distinct categories using a clustering algorithm as depicted in Figure 7 (see Materials and Methods). Each row in Figure 7 shows the normalized integrated power for each LFP recording, and each column represents the six intervals in the SCT sequence (three for the synchronization and three for the continuation phase). The first category may encode the ordinal structure of the task sequence because the LFPs spectral power showed greater modulations during one or two consecutive elements of the sequence and were considered ordinal-selective (Table 2; Fig. 7). For example, the initial group of LFPs with high (black) integrated power on the first interval of the synchronization phase was clustered as ordinal-selective to S1. These LFPs confirm the wellknown ordinal sequential movement activity in the basal ganglia (Kermadi and Joseph, 1995; Mushiake and Strick, 1995) is also present during the execution of the SCT. In contrast, the second category consisted of LFPs that showed high oscillatory activity during the whole synchronization or continuation phase of the SCT (Fig. 7, Sync or Conti on the right legend). This type of phase-selective response was associated with the temporal information processing during sensoryguided (synchronization) or internally driven (continuation) production of rhythmic movements.

We fitted Gaussian functions to the integrated power of the $\beta$ - and $\gamma$-bands as a function of the serial order of the SCT, to detect whether tuning functions occurred also for serial order as they occurred for duration. As expected, a large proportion of LFPs were significantly tuned to the serial order (Table 3$)$. There was a significant bias ( $\chi^{2}$ test, $p<0.001$ ) toward the continuation phase in the preferred serial order for the $\beta$-band across interval marker conditions (Fig. 8, filled bars). In contrast, the sequential tuning in the $\gamma$-band showed a significant bias ( $\chi^{2}$ test, $p=0.0016$ ) toward the synchronization phase (Fig. 8 , filled bars). Overall, these findings support the notion that the internal generation of rhythmic movements was associated with the entrainment of putaminal circuits that oscillate in the $\beta$-frequencies.

On the other hand, spikefield synchrony in the $\gamma$-band may be used for computations of sensory timed movements. A prediction of this hypothesis is that, if we align the spectrograms to the times of stimuli instead of tapping times as in the previous anal- 
ysis, we would find more LFPs with tuned $\gamma$ activity. Indeed, when we performed the analyses using stimulus-aligned spectrograms, we found that there were more LFPs with sequence-tuned $\gamma$-activity, whereas the number of LFPs with tuned $\beta$-activity was similar to the one obtained from tap-aligned spectra (Fig. 8, empty bars). Furthermore, the tuning bias toward the synchronization phase of the SCT was larger for the $\gamma$-spectrograms aligned to the stimulus than to the taps ( $\chi^{2}$ test, $p<0.0001$ ). In contrast, for $\beta$ the distribution of preferred serial order was biased toward the continuation phase only when tap-aligned $\left(\chi^{2}\right.$ test, $p<$ $0.0001)$ and similar across task phases when stimulus-aligned $\left(\chi^{2}\right.$ test, $p=$ $0.2121)$. To assess overall statistical effects, we constructed a binary-logistic dependent variable to be used to performed a Generalized Linear Model analysis, the value of the binary variable was 1 when tuning was found in a given task phase (S or C) using a given alignment (Taps or Stimuli) for each frequency band $(\beta$ or $\gamma$ ), 0 otherwise. The model included the phase $\times$ band, phase $\times$ alignment, task $\times$ band $\times$ alignment interactions. The analysis revealed significant effects of the phase $\times$ band (Wald $\chi^{2}=16.645, p<0.001$ ) and phase $\times$ alignment (Wald $\chi^{2}=93.053, p<0.001$ ) interactions, but only a marginal effect on the three-way task $\times$ band $\times$ alignment interaction (Wald $\chi^{2}=5.385, p=0.068$ ).

From the results shown in Figure 8, we can ask how many LFPs are tuned to serial order when the spectrograms are aligned to the stimuli and/or the tapping times. For each frequency band, we found a population of LFPs for which serial-order tuning was similar between the two alignments (resistant-tuned, green overlap in the Venn diagrams of Fig. 9A), and two additional populations that showed serial-order tuning for only one alignment (stimulus-tuned and tap-tuned; red and blue circles, respectively, in the Venn diagrams of Fig. 9A). The proportion between these three populations was significantly different across frequency bands ( $\chi^{2}$ test, $p<0.0001$ ). The distribution of preferred serial order for the $\beta$-activity was clearly tuned for the continuation phase when tap-aligned; in contrast, the stimulus-tuned LFPs in this $\beta$-band were less numerous and did not show a bias toward the continuation phase (Fig. 9B). A Kolmogorov-Smirnov test revealed a significant difference between tap- and stimulusaligned preferred serial order $\beta$-band distributions $(p<0.0001)$. For the $\gamma$-activity, we found an inverse relationship, namely, when stimulus-aligned the LFPs tuned were more numerous and more biased toward the synchronization phase than when tapaligned (Fig. 9B). The distributions of preferred serial order for the $\gamma$-band were significantly different when tap- versus stimulus-aligned (Kolmogorov-Smirnov test, $p=0.0449$ ). On the contrary, the resistant-tuned population showed similar distributions for both alignments in both frequency bands (Fig. $9 C$ ), with no significant difference across alignments (Kolmogorov-Smirnov test, $\beta, p=0.96 ; \gamma, p=0.2$ ). Together, these results strongly support the hypothesis that $\gamma$-activity is sensory-driven, in accordance with studies that suggest that $\gamma$-band activity in the striatum occurs in association with the integration of sensory

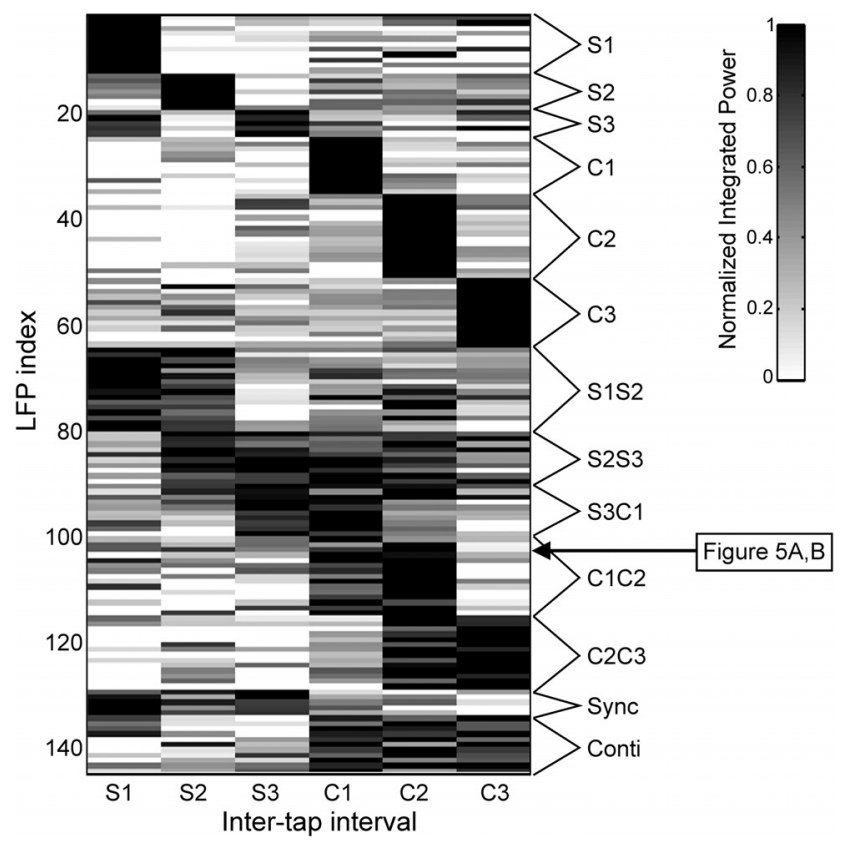

Figure 7. LFP selectivity to the serial order and task phase during the SCT. K-means clustering of the normalized probability of power increments in the $\beta$-band for the LFP recordings that showed significant effects on serial order (Friedman test) during the visual interval marker condition. The data were classified as sequence selective to one, two or three consecutive elements of the SCT according to the magnitude of the power modulations (grayscale). Each row corresponds to one LFP recording, and each column corresponds to one element of the SCT sequence. The arrow corresponds to the LFP recording shown in Figure $5 A, B$.

information and associative learning (Howe et al., 2011), whereas $\beta$-activity is related to the endogenously driven tapping behavior.

The coherence in the oscillatory activity was local during $\gamma$ bursting but global during $\beta$ activity

There is evidence suggesting that $\gamma$-oscillations are locally generated, whereas $\beta$-bursts are generated by broad circuits within a structure (Courtemanche et al., 2003; Howe et al., 2011), or even spread across distant structures (Kay and Beshel, 2010; Leventhal et al., 2012). Hence, we wanted to know whether the LFPs tuned for serial order showed the same degree of anatomical specificity between bands. First, we found that a larger proportion of the 
Table 2. Number of LFPs whose integrated power during the visual and auditory conditions of the SCT was classified as follows: serial order selective, responding during one or two consecutive elements of the six interval sequence; or phase selective, responding during the whole synchronization or continuation phase

\begin{tabular}{llllll}
\hline & $\beta$ & & & $\gamma$ \\
\cline { 2 - 3 } \cline { 6 - 7 } Classification & Auditory & Visual & & Auditory & Visual \\
\hline Serial order selective & 125 & 128 & & 110 & 99 \\
Phase selective & 15 & 17 & & 25 & 25 \\
Total analyzed & 168 & 181 & & 150 & 138 \\
\hline
\end{tabular}

Table 3. Number of LFP recordings that showed significantly tuned modulations in the $\beta$ - and/or $\gamma$-band

\begin{tabular}{|c|c|c|c|c|c|c|}
\hline \multirow[b]{2}{*}{ Modality } & \multicolumn{2}{|c|}{ Duration tuned } & \multicolumn{2}{|c|}{ Sequence tuned } & \multicolumn{2}{|c|}{$\begin{array}{l}\text { Duration and } \\
\text { sequence tuned }\end{array}$} \\
\hline & Auditory & Visual & Auditory & Visual & Auditory & Visual \\
\hline$\beta$ & 47 & 64 & 49 & 51 & 67 & 67 \\
\hline$\gamma$ & 18 & 18 & 20 & 23 & 13 & 10 \\
\hline$\beta$ and $\gamma$ & 8 & 6 & 4 & 8 & 5 & 4 \\
\hline
\end{tabular}

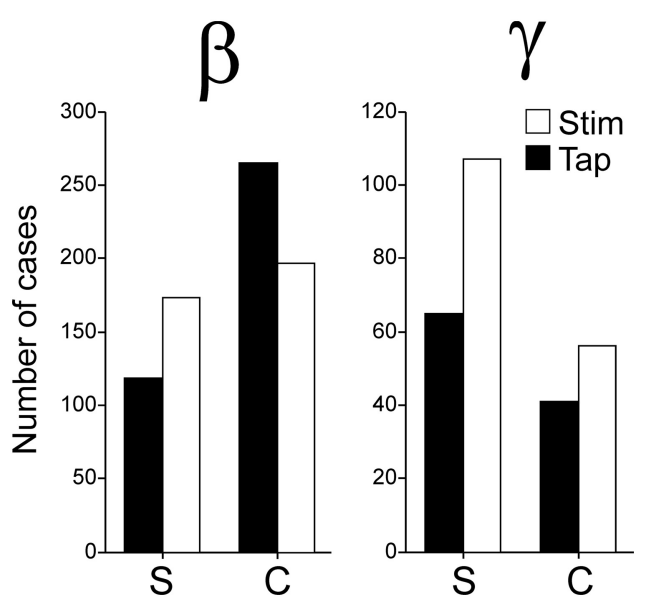

Figure 8. Total number of LFPs with preferred serial order during the synchronization $(S)$ or continuation (C) phase of the SCT across frequency bands ( $\beta$ or $\gamma$ ) pooling auditory and visual marker data. Filled and empty bars represent tuned LFPs when aligned to tap times or stimuli times, respectively. The difference between task phases was significant for tap-aligned LFPs in both bands ( $\chi^{2}$ test, $\left.p<0.002\right)$, but only for the $\gamma$-band for the stimulus-aligned LFPs $\left(\chi^{2}\right.$ test, $p<0.0001)$.

LFPs tuned to serial order were recorded simultaneously in the $\beta$-band (auditory, 29.47\%; visual, 34.03\%) than the $\gamma$-band (auditory, $4.5 \%$; visual, $4.2 \%$ ). This is an indirect measure of global entrainment in the $\beta$-band and local $\gamma$-activity because we recorded the simultaneous activity of seven electrodes during task performance. Next, for each band, we analyzed the coherence between pairs of simultaneously recorded LFPs that were sequence-tuned as a function of the distance between recording sites. Our electrodes had a linear arrangement with an interelectrode separation of $300 \mu \mathrm{m}$. Thus, knowing the depth at which every electrode was located during the recording session, we were able to estimate the distance between electrode tips. The results showed that the coherence magnitude was larger for $\beta$ - than for $\gamma$-band activity, with a small decrease in coherence magnitude as a function of the distance between recording sites in both bands (Fig. 10A). A two-way ANOVA for coherence magnitude showed significant main effects for band $\left(F_{(1,768)}=469.35, p<0.0001\right)$ and intertip distance $\left(F_{(6,768)}=5.3, p<0.0001\right)$, as well as in the band $\times$ distance interaction $\left(F_{(6,768)}=3.3, p=0.0033\right)$. In addition, the absolute phase angle between coherent oscillations was
A
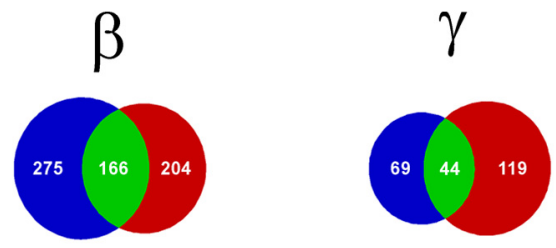

B
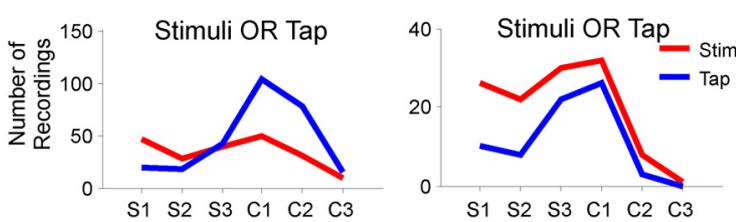

C
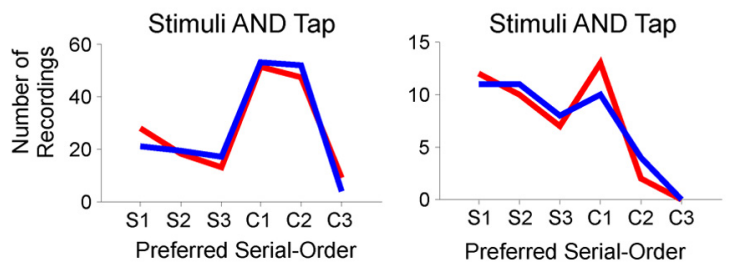

Figure 9. Distribution of preferred serial order across frequency bands $(\beta$ or $\gamma$ ) and signal alignments (Tap or Stimuli). $\boldsymbol{A}$, Venn diagrams showing the different sets of serial order tuned LFPs, namely, only tuned when aligned to tapping times (blue), only tuned when aligned to stimuli times (red), or tuned in both alignments (green). $\boldsymbol{B}$, Distributions of the preferred serial order of LFPs tuned when tap-aligned only (blue) or stimulus-aligned only (red). The six elements of the task sequence are depicted in the horizontal axis: S1-S3, the synchronization phase; and C1-C3, the continuation phase. C, Preferred serial order of LFPs from the green sets in $\boldsymbol{A}$, namely, for those LFPs that were tuned to serial order when aligned to both the tap (blue) and the stimulus (red).

larger for the $\gamma$-than the $\beta$-band, with a larger increase in the phase of coherence as a function of recording distance for the $\gamma$ than the $\beta$-band (Fig. 10B). Significant main effects of band $\left(F_{(1,756)}=70.35, p<0.0001\right)$ and intertip distance $\left(F_{(6,756)}=\right.$ $4.62, p=0.0001)$, as well an in the band $\times$ distance interaction $\left(F_{(6,756)}=2.93, p=0.0079\right)$ were found on the phase angle. Hence, $\beta$-oscillations were largely coherent and in phase between recording distances spanning as much as $7.3 \mathrm{~mm}$, whereas $\gamma$-band activity showed both small coherence between recording sites and a large increment in the phase as the distance between electrode tips increased. Together, these results support the notion that $\gamma$-oscillations are locally generated, whereas $\beta$-activity involves synchronous activity of large putaminal ensembles.

The spiking activity of putaminal neurons is entrained with $\boldsymbol{\beta}$ and $\gamma$ oscillations

It was important to establish whether the recorded LFP oscillations were related to putaminal neural activity at the recording site, and not simply volume-conducted from nearby structures without any relationship to the neostriatal processing of temporal and sequential information. To tackle this issue, we performed a spike-LFP phase locking analysis. First, we looked for periods of high amplitude bursts of oscillatory activity $(z$-score $>1.96)$ on the bandpass filtered and $z$-scored LFP traces for $\beta$ - and $\gamma$-bands independently. Then, we determined the phase between spikes and the oscillatory bursts (Fig. 11A) and tested whether the spiking activity was significantly phase-locked with the oscillations recorded by the same electrode (Rayleigh test, $p<0.05$ ). We found that $\sim 16 \%$ of all neurons (total $n=520$ ) were phaselocked during bursts of $\beta$ activity, and this proportion was even higher, $\sim 27 \%$, during bursts of $\gamma$-activity. When the proportion of phase-locked neurons was calculated using only LFPs that were 
tuned to duration and/or serial order $(\beta \mathrm{A}, n=406 ; \beta \mathrm{V}, n=465$; $\gamma \mathrm{A}, n=160 ; \gamma \mathrm{V}, n=154)$, we found an increase to $\sim 42 \%$ during bursts of $\beta$ activity (auditory, $41.63 \%$; visual, $42.15 \%$ ), and the proportion was nearly the same during $\gamma$-activity (auditory, $42.85 \%$; visual, $43.95 \%$ ). On the other hand, the average phase of the spikes during bursts of activity remained almost the same independently of the frequency band (Fig. $11 B$ ), occurring before the troughs $\left(270^{\circ}\right)$ of the oscillations (mean phase: $\beta, 204.5^{\circ} ; \gamma$, $203.3^{\circ}$ ). These results show a clear relationship between spiking responses and oscillations in both frequency bands and suggest that the oscillatory activity is functionally related with the local striatal activity and the cell tuning during SCT performance, a phenomenon that we describe below.

\section{On the relations between spiking and oscillatory activity for interval and serial-order tuning}

We also determined the tuning properties on the discharge rate of putaminal cells recorded in the same electrodes than the LFPs during the execution of SCT. To this end, we performed an initial ANCOVA where the discharge rate was used as the dependent variable, the discharge rate during the key holding control epoch as the covariate, and the interval duration or the serial order of the SCT as the factor. Because the duration of target intervals varied systematically in our tasks, we could not use a fixed temporal window to compute the discharge rate of the cells. Alternatively, we used the Poisson train analysis (Merchant et al., 2001) to identify the periods of cell activation within each produced interval. Next, we fitted Gaussian functions to the discharge rate of cells as a function of interval or serial order on the cells with significant ANCOVA effects on the corresponding factor. Of 366 putaminal neurons recorded during the SCT, 98 and 78 were tuned for interval during the auditory and visual conditions, respectively, whereas 84 and 80 neurons were tuned for serial order during the auditory and visual conditions, respectively. These results indicate that the cells in the putamen show similar functional properties to the medial premotor neurons (Merchant et al., 2013b), implicating the CBGT in the encoding of the temporal and sequential structure of the SCT (Merchant and Honing, 2014).

As a subsequent step, we compared the tuning properties of cells and LFPs in the putamen. The distribution of preferred intervals across the population of significantly tuned cells is displayed as a black line in Figure 12A, together with the distribution
A

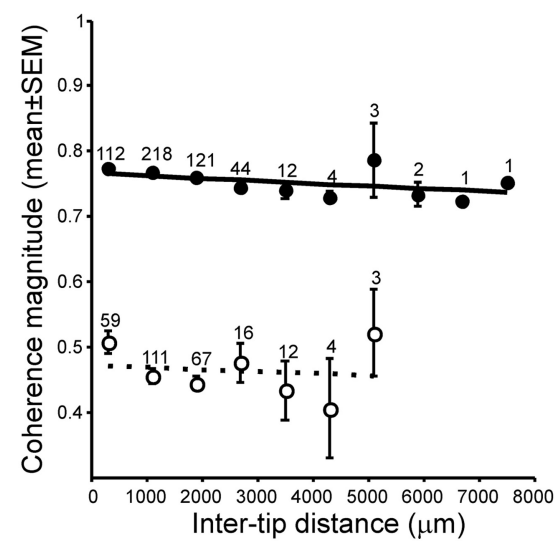

Figure 10. Coherence analysis. $A$, Mean coherence magnitude $( \pm S E M)$ as a function of the distance between the electrode tips. Distance bins are $800 \mu \mathrm{m}$ wide. Numbers above each dot indicate the number of cases (same for magnitude and phase). $\boldsymbol{B}$, Mean coherence phase angle ( \pm SEM) as a function of distance. Open circles represent $\beta$-band; filled circles represent $\gamma$-band. Dotted and solid lines indicate the linear regression fits for $\beta$ - and $\gamma$-band, respectively.
B

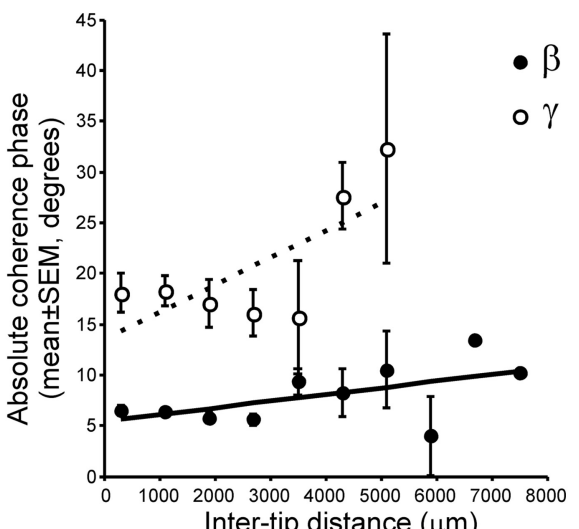

Inter-tip distance $(\mu \mathrm{m})$
A

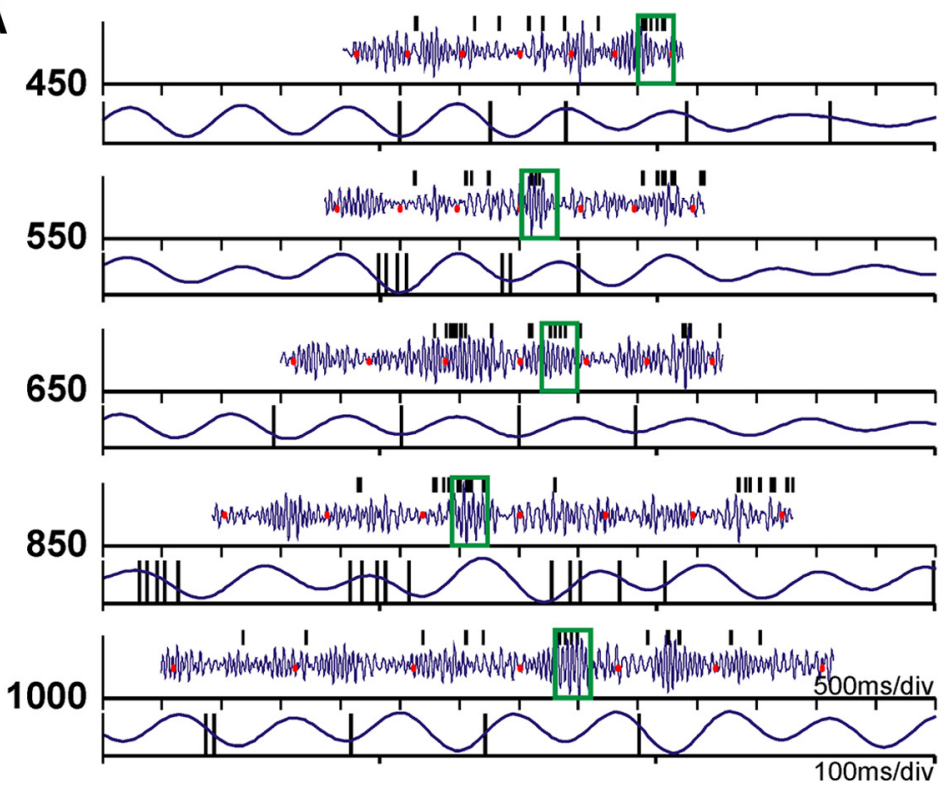

B
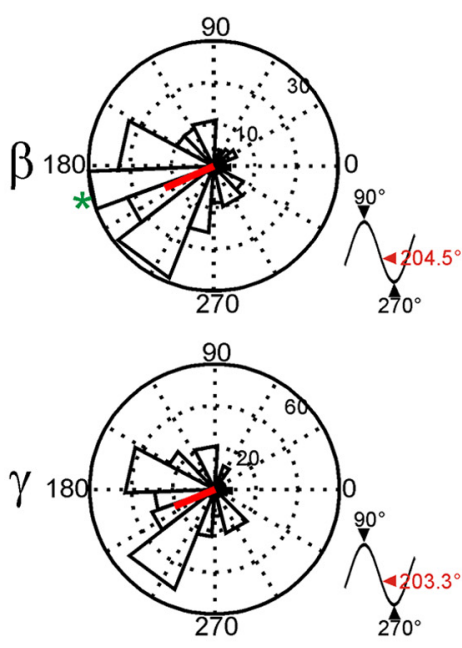

Figure 11. Phase locking of unitary spikes with LFP oscillations. $\boldsymbol{A}$, Representative $\beta$ bandpass filtered and normalized LFP traces (blue) and the corresponding spikes from a single unit in the same recording site (black ticks). Tapping times are displayed as red dots. For each target interval, the top shows the LFP signal of a whole trial, where the segment enclosed within the green box is amplified in the bottom. $\boldsymbol{B}$, Phase histograms showing the mean phases of all significantly phase-locked units to $\beta$ or $\gamma$ LFP activity. The red line indicates the mean resultant vector of the population. Bottom right insets, Location of the mean population phase in a standard sinusoid. The green asterisk in the $\beta$ histogram indicates the phase of unit in $\boldsymbol{A}$. 
A

B
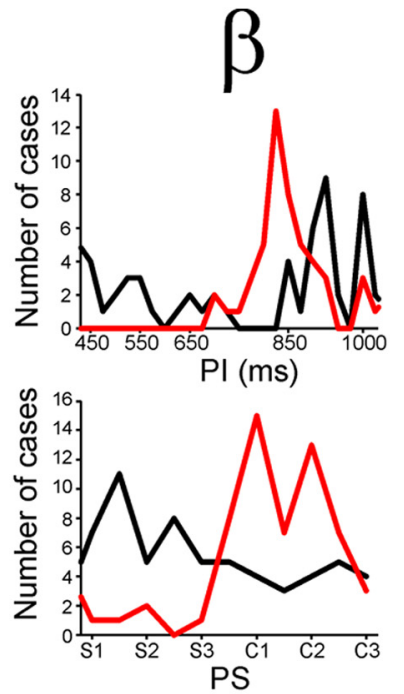

C

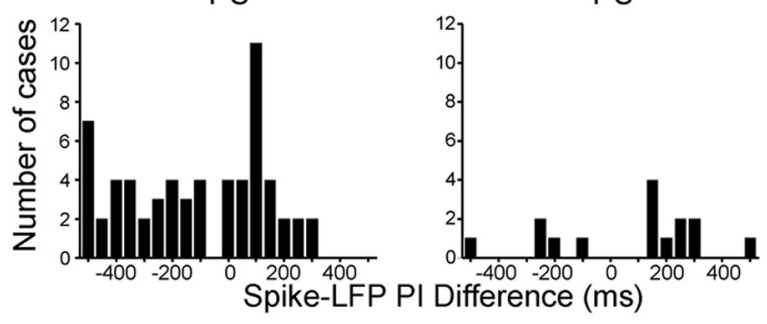

D

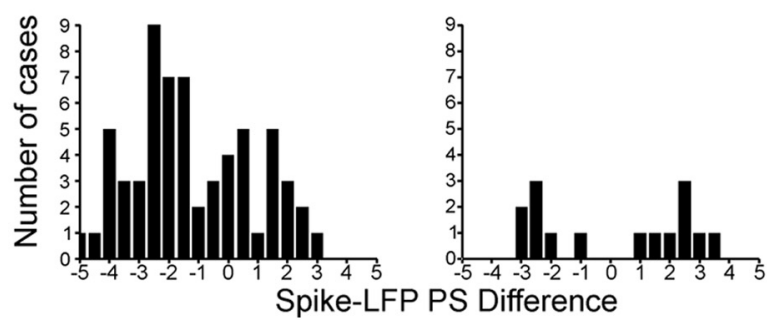

Figure 12. Distributions of preferred intervals (PI) and preferred serial order (PS) for cells and LFPs simultaneously recorded in the same electrode. $\boldsymbol{A}$, Distributions of PI for spiking activity (black line) and $\beta$ (left) or $\gamma$ (right) LFPs (red line) that were tuned to interval. $\boldsymbol{B}$, Distributions of PS for spiking activity (black line) and $\beta$ (left, red line) or $\gamma$-band oscillations (right, red line) that were tuned to serial order. $\boldsymbol{C}$, Distributions of the difference in PI between spikes and LFPs for the $\beta$ - (left) and $\gamma$-band (right). D, Distributions of the PS difference between spikes and LFPs for the $\beta$ - (left) and $\gamma$-band (right).

of preferred intervals for the oscillatory activity of the LFPs recorded in the same electrodes, for the $\beta$ - and $\gamma$-bands independently (red line, Fig. 12A, left and right, respectively). Three important facts can be extracted from these data. First, more cells were interval tuned for electrodes where also the LFPs were tuned for the $\beta$-with respect to the $\gamma$-band ( $\chi^{2}$ test, $\left.p<0.0001\right)$. This suggests that the oscillatory activity in $\beta$ is more closely associated with the cell activity encoding interval duration than the $\gamma$-band. Second, although the distributions of preferred intervals for both the spiking and $\beta$-activity are tilted toward large intervals, the distribution for the cell activity peaks at smaller intervals (peak $825 \mathrm{~ms}$ ) than the corresponding LFPs in the $\beta$-band (peak at 900 $\mathrm{ms}$ ). Indeed, the difference in preferred intervals between spikes and $\beta$ LFPs was tilted toward negative values with a median of $-98 \mathrm{~ms}$, indicating that the spikes showed significantly smaller preferred intervals than their simultaneously recorded $\beta$ LFPs $(t$ test, $p<0.0001$; Fig. $12 C$, left). Finally, the interval tuning of cells and the corresponding $\gamma$ activity, when present, was similar in these two electrophysiological signals ( $t$ test, $p=0.28$; Fig. $12 \mathrm{~A}$,
A

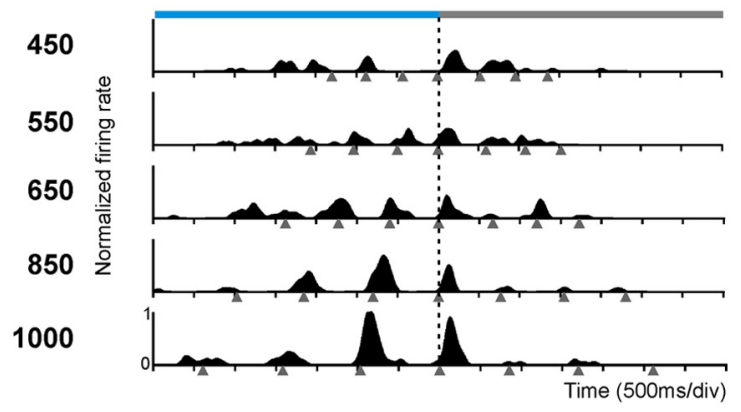

B

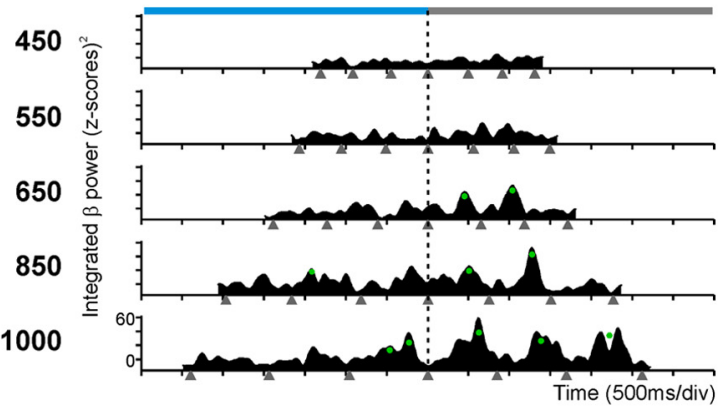

C

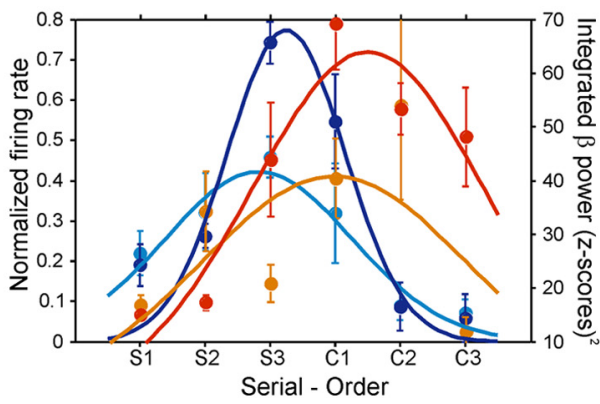

Figure 13. Serial-order selectivity of the activity of a cell and the $\beta$ power that were simultaneously recorded in the same electrode. $A$, Spike density functions of a cell that was selective for long durations through the last interval of the synchronization and the first interval of the continuation phase of the SCT. $\boldsymbol{B}$, Integrated power of the corresponding $\beta$-band activity that was tuned also for long durations, but during the first two intervals of the continuation phase. This implies that the cell activity preceded the changes in the power of $\beta$ oscillations. Same conventions as in Figure 5. C, Serial-order tuning in the spike density functions and in the integrated $\beta$ power. Dots are the mean \pm SEM, and lines indicate the fitted Gaussian functions. Tuning functions were calculated for each target interval across the serial order sequence S1-C3 and are color-coded (inset). Only fittings for the intervals of 850 and 1000 ms are shown.

right), with a distribution of the difference in preferred intervals between spikes and $\gamma$ LFPs slightly tilted toward positive values (median, 160 ms; Fig. 12C, right).

Similar properties were observed for the relation between the serial-order tuning of the spiking and the oscillatory signals recorded simultaneously, with a stronger relation between spikes and $\beta$ - than spikes and $\gamma$-band $\left(\chi^{2}\right.$ test, $\left.p<0.0001\right)$. The distribution of preferred serial order for the $\beta$-band was strongly tilted toward the continuation phase (median, 4.3; Fig. 12B, left red), whereas the corresponding distribution for the cell activity was clearly skewed toward the synchronization phase of the SCT (median, 2.4; Fig. 12B, left black), with a significant difference between the two distributions (Kolmogorov-Smirnov test, $p<$ $0.00001)$. Again, the difference in preferred serial order between spikes and $\beta$ LFPs was tilted toward negative values with a median of -1.61 , demonstrating that spikes discharged before the changes in $\beta$-power that were related to the serial order of the SCT (Fig. 12D, left). Indeed, Figure $13 A$ shows the instantaneous discharge rate of a cell that was selective for long durations 
Table 4. Number of recordings that showed LFP power and/or spike activity that were tuned to duration and serial order ${ }^{a}$

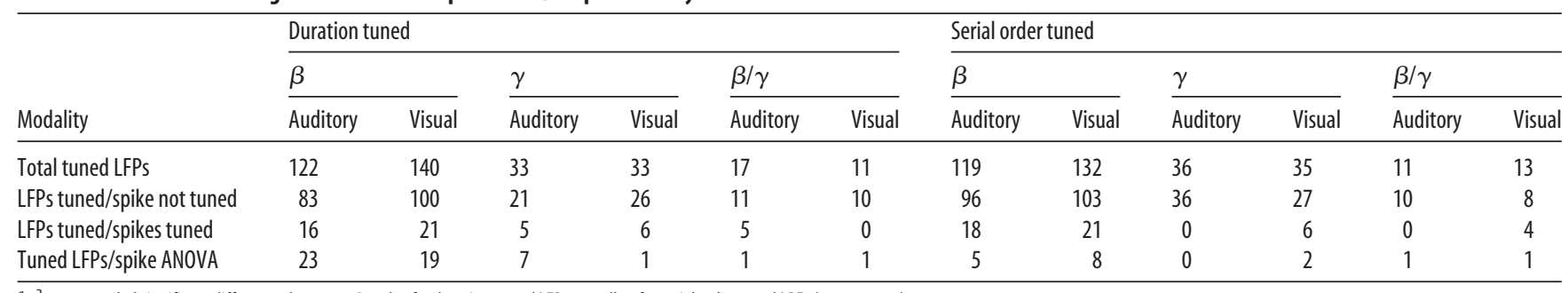

${ }^{a} \chi^{2}$ tests revealed significant differences between $\beta$ and $\gamma$ for duration-tuned LFPs as well as for serial order tuned LPFs $(p<0.0001)$.

through the last interval of the synchronization and the first interval of the continuation phase of the SCT. Consistent with the data of Figure 12, the integrated power in $\beta$-band for the LFP recorded in conjunction with the cell, the oscillatory activity was tuned for long durations, predominantly during the first two intervals of the continuation phase (Fig. 13B). This implies that the cell activity preceded the serial order changes in the power of $\beta$. Finally, there was a weak association between the cell response and the $\gamma$-oscillations that were selective to serial order. However, when present, the preferred serial order was similar between the two signals ( $t$ test, $p=0.96$; Fig. $12 B$, right), and the difference in preferred serial order between spikes and $\gamma$-oscillations was centered $\sim 0$ (median, $0.13 \mathrm{~ms}$; Fig. $12 D$, right). Together, these findings suggest that the oscillatory activity in $\beta$ was more associated with the cell activity encoding interval duration and serial order than the $\gamma$-band (see also Table 4).

\section{Discussion}

This paper found tuning for interval and/or serial order as an orderly change in the power of transient modulations in the $\beta$ and $\gamma$-bands across putaminal LFPs during the execution of the SCT. A large number of LFPs were tuned to duration, especially in the $\beta$-band, and all possible preferred durations were represented in both bands. Remarkably, there was a strong bias in the serial order tuned sites toward the continuation phase for the $\beta$-band when the activity was aligned to the taps; whereas in $\gamma$-band, the bias was toward the synchronization phase of the SCT, especially when the spectrograms were aligned to the stimuli. In addition, a group of putaminal neurons became entrained to $\beta$ - and $\gamma$-oscillations, and strong tuning relations between LFPs and neurons were observed, particularly between the $\beta$-band and the spikes, suggesting that both rhythms are relevant for the firing activity of this area. Analysis of coherence between simultaneously recorded LFPs tuned to serial order showed that $\beta$-oscillations were largely coherent and in-phase at large recording distances, whereas $\gamma$-band activity showed small coherence and a large increment in the phase as a function of the interelectrode distance. Hence, the results are consistent with the hypothesis that $\gamma$ is used for local computations associated with the sensory processing inherent to the synchronization phase, whereas $\beta$ oscillations are used for high-level interactions involving large areas of the putamen, and probably also other elements of the CBGT circuit, during the execution of internally driven rhythmic behaviors.

Neural tuning is widely used to encode sensory, cognitive, and motor information (deCharms and Zador, 2000). Neurons in cortical and subcortical structures carry information about a limited range of values or a particular behavioral feature, with an orderly decrease in discharge rate around a preferred value (Merchant et al., 2012). In addition, tuning can be observed in both the cells' discharge rate and the power of oscillatory activity of LFPs in different areas and for different behavioral features, such as tuning to the direction of movement in M1 (Georgopoulos et al., 1982; Paninski et al., 2004) or speed and direction of visual stimuli in MT (Liu and Newsome, 2006), indicating a functional coupling between the two signals. The match in the feature preference between LFP and single neurons recorded from the same electrode is explained by the signal pooling from neuronal groups with similar stimulus preferences by the LFP (Lashgari et al., 2012). Nevertheless, the tuning association between spiking activity and LFPs is not always obvious because the latter is a complex signal that depends on the following factors: the input activity of an area in terms of population excitatory and IPSPs, the regional processing of the microcircuit surrounding the recording electrode, the cytoarchitecture of the studied area, and the temporally synchronous fluctuations of the membrane potential in large neuronal aggregates (Buzsáki et al., 2012). Despite this complexity, it has become evident that nonspiking signals can provide a source of information about behavior (Mehring et al., 2003; Schalk et al., 2007; Waldert et al., 2008; Zhuang et al., 2010). In the present study, we show that putaminal neurons became entrained to $\beta$ - and $\gamma$-oscillations, indicating that both bands are relevant to the firing patterns of putaminal cells and that the tuning to duration and/or serial order in the rhythmic activity of LFPs were generated, at least in part, within the putamen. Indeed, a detailed comparison in the tuning properties of spikes and LFP oscillations recorded from the same electrode showed strong relations between these two signals during the SCT. The oscillatory activity in $\beta$ was more associated with the cell activity encoding interval duration and serial order than the $\gamma$-band, and the cell activity preceded the changes in the power of $\beta$. Similar observations have been reported in the motor system during reaching and grasping behaviors (Murthy and Fetz, 1996; Brown and Williams, 2005; Witham and Baker, 2012).

It has been suggested that the corticostriatal circuits play an important role in interval timing. The Striatal Beat-Frequency Theory (Matell and Meck, 2004; Buhusi and Meck, 2005; Meck, 2006) proposes that timing can emerge by coincidence detection processes for which corticostriatal circuits are particularly well suited. In the present paper, we found that the spiking responses and the rhythmic activity in the $\beta$ - and $\gamma$-bands in the putamen were tuned to specific durations, suggesting the existence of duration-specific circuits as predicted by behavioral studies (Wright et al., 1997; Nagarajan et al., 1998; Bartolo and Merchant, 2009). Although all the tested durations were represented across cells and LFPs, there was a bias in the distribution of preferred durations toward intervals $\sim 800 \mathrm{~ms}$, which is similar to the bias of preferred durations for single cells in the medial premotor cortex (MPC) (Merchant et al., 2013b). This bias could be associated with the preferred tempo in Rhesus monkeys. Indeed, the preferred tempo in humans is $\sim 600 \mathrm{~ms}$ (Fraisse, 1982; Collyer et al., 1994), and a recent study showed that a chimpanzee had also a preferred tempo of $600 \mathrm{~ms}$ (Hattori et al., 2013). Now, 
neurons in MPC show responses that multiplex the ordinal and temporal structure of rhythmic movements (Merchant et al., 2013b). In addition, independent studies have described neural responses associated to interval duration or organization of movement sequences in the neostriatum (Kermadi and Joseph, 1995; Miyachi et al., 1997; Meck et al., 2008; Jin et al., 2009) and MPC (Tanji and Shima, 1994; Mita et al., 2009). Furthermore, patients with Parkinson's disease (PD) have clear deficiencies in the organization of sequential and temporal aspects of motor behavior (Ferraro et al., 1993; Harrington et al., 1998; Helmuth et al., 2000; Merchant et al., 2008a). MPC is strongly connected with the putamen (Haber, 2003; Lehéricy et al., 2004) and is a critical node of the CBGT circuit (Parent and Hazrati, 1995; Middleton and Strick, 2000). Hence, these previous observations and the current data suggest that tuning to duration and serial order is an encoding strategy used along the CBGT circuit to represent the temporal and sequential structure of rhythmic movements.

Abnormal $\beta$-oscillations have been found in the CBGT circuit of PD patients (Levy et al., 2002; Weinberger et al., 2009). In addition, $\beta$-power is reduced by treatments that improve bradykinesia and rigidity, such as dopamine replacement therapy (Brown et al., 2001; Levy et al., 2002) and deep brain stimulation (Kühn et al., 2008). Hence, the current hypothesis is that the abnormally strong $\beta$ in PD may reflect overstabilization of the CBGT network, producing pathological persistence of the current motor state (Hammond et al., 2007). Accordingly, the largescale communication between areas through $\beta$-activity in healthy subjects has been associated with endogenously driven behaviors (Engel and Fries, 2010; Leventhal et al., 2012). A recent MEG study involving internalized timing of an auditory metronome showed phasic increments of $\beta$-activity, across the auditory and motor systems, that were dependent on the interstimulus interval and peaked just before each stimulus (Fujioka et al., 2012). Furthermore, transient increases of $\beta$-activity have been shown also during a beat perception task (Iversen et al., 2009). These observations suggest that $\beta$-activity is associated with the internal representation of sensorimotor and cognitive states, including the endogenous processing of temporal events. Our present results strongly support this hypothesis. Most of $\beta$-bursts that were tuned to serial order showed a preference for the continuation phase of the SCT, which is characterized by the internal generation of rhythmic movements. Consequently, these $\beta$-oscillations could be associated with the maintenance of a rhythmic set and the dominance of an endogenous reverberation in the CBGT circuit, which in turn could generate internally timed movements and override the effect of external events.

On the other hand, $\gamma$-bursts have been associated with sensory cued bottom-up behaviors in cortical and subcortical areas (Kopell et al., 2000; Berke, 2009; Fries, 2009). We found that $\gamma$-band modulations that were tuned to serial order showed a strong bias toward the synchronization phase when aligned to the stimuli. Hence, our results are consistent with the notion that $\gamma$-band predominates during sensory processing (Fries, 2009) or when changes in the sensory input or cognitive set are expected (Engel and Fries, 2010). The local processing of visual or auditory cues in the $\gamma$-band during rhythmic movements may serve for binding neural ensembles that processes sensory and motor information within the putamen (Fries et al., 2007; Uhlhaas et al., 2009). This sensorimotor integration could then be transmitted throughout the CBGT circuit. Needless to say, more experiments are required to get a better understanding on how oscillatory processes with different carrier frequencies (i.e., $\gamma$ and $\beta$ ) can be involved in bottom-up (e.g., synchronization phase) and top-down (e.g., continuation phase) processing and how they might actually interact at the local and global stages within the CBGT circuit.

\section{References}

Baker SN, Olivier E, Lemon RN (1997) Coherent oscillations in monkey motor cortex and hand muscle EMG show task-dependent modulation. 501:225-241.

Bartolo R, Merchant H (2009) Learning and generalization of time production in humans: rules of transfer across modalities and interval durations. Exp Brain Res 197:91-100. CrossRef Medline

Batschelet E (1981) Circular statistics in biology. London: Academic.

Berens P (2009) CircStat: a MATLAB Toolbox for circular statistics. J Stat Softw 31:1-21.

Berke JD (2009) Fast oscillations in cortical-striatal networks switch frequency following rewarding events and stimulant drugs. Eur J Neurosci 30:848-859. CrossRef Medline

Brown P, Williams D (2005) Basal ganglia local field potential activity: character and functional significance in the human. Clin Neurophysiol 116: 2510-2519. CrossRef Medline

Brown P, Oliviero A, Mazzone P, Insola A, Tonali P, Di Lazzaro V (2001) Dopamine dependency of oscillations between subthalamic nucleus and pallidum in Parkinson's disease. J Neurosci 21:1033-1038. Medline

Buhusi CV, Meck WH (2005) What makes us tick? Functional and neural mechanisms of interval timing. Nat Rev Neurosci 6:755-765. CrossRef Medline

Buzsáki G (2006) Rhythms of the brain. New York: Oxford UP.

Buzsáki G, Anastassiou CA, Koch C (2012) The origin of extracellular fields and currents-EEG, ECoG, LFP and spikes. Nat Rev Neurosci 13:407-420. CrossRef Medline

Collyer CE, Broadbent HA, Church RM (1994) Preferred rates of repetitive tapping and categorical time production. Percept Psychophys 55:443453. CrossRef Medline

Courtemanche R, Fujii N, Graybiel AM (2003) Synchronous, focally modulated beta-band oscillations characterize local field potential activity in the striatum of awake behaving monkeys. J Neurosci 23:11741-11752. Medline

deCharms RC, Zador A (2000) Neural representation and the cortical code. Annu Rev Neurosci 23:613-647. CrossRef Medline

Donnet S, Bartolo R, Fernandes JM, Cunha JP, Prado L, Merchant H (2014) Monkeys time their pauses of movement and not their movementkinematics during a synchronization-continuation rhythmic task. J Neurophysiol Submitted.

Draper NR, Smith H (1981) Applied Regression Analysis. New York: Wiley.

Engel AK, Fries P (2010) Beta-band oscillations-signalling the status quo? Curr Opin Neurobiol 20:156-165. CrossRef Medline

Ferraro FR, Balota DA, Connor LT (1993) Implicit memory and the formation of new associations in nondemented Parkinson's disease individuals and individuals with senile dementia of the Alzheimer type: a serial reaction time (SRT) investigation. Brain Cogn 21:163-180. CrossRef Medline

Fraisse P (1982) Rhythm and tempo. In: Psychology of music (Deutsch D, ed), pp 149-180. New York: Academic.

Frey S, Pandya DN, Chakravarty MM, Bailey L, Petrides M, Collins DL (2011) An MRI based average macaque monkey stereotaxic atlas and space (MNI monkey space). Neuroimage 55:1435-1442. CrossRef Medline

Fries P (2009) Neuronal gamma-band synchronization as a fundamental process in cortical computation. Annu Rev Neurosci 32:209-224. CrossRef Medline

Fries P, Nikoliæ D, Singer W (2007) The gamma cycle. Trends Neurosci 30:309-316. CrossRef Medline

Fujioka T, Trainor LJ, Large EW, Ross B (2012) Internalized timing of isochronous sounds is represented in neuromagnetic beta oscillations. J Neurosci 32:1791-1802. CrossRef Medline

Georgopoulos AP, Kalaska JF, Caminiti R, Massey JT (1982) On the relations between the direction of two-dimensional arm movements and cell discharge in primate motor cortex. J Neurosci 2:1527-1537. Medline

Gibbon J, Malapani C, Dale CL, Gallistel C (1997) Toward a neurobiology of temporal cognition: advances and challenges. Curr Opin Neurobiol 7:170-184. CrossRef Medline

Haber SN (2003) The primate basal ganglia: parallel and integrative networks. J Chem Neuroanat 26:317-330. CrossRef Medline

Hammond C, Bergman H, Brown P (2007) Pathological synchronization in 
Parkinson's disease: networks, models and treatments. Trends Neurosci 30:357-364. CrossRef Medline

Harrington DL, Haaland KY, Knight RT (1998) Cortical networks underlying mechanisms of time perception. J Neurosci 18:1085-1095. Medline

Harrington DL, Zimbelman JL, Hinton SC, Rao SM (2010) Neural modulation of temporal encoding, maintenance, and decision processes. Cereb Cortex 20:1274-1285. CrossRef Medline

Hattori Y, Tomonaga M, Matsuzawa T (2013) Spontaneous synchronized tapping to an auditory rhythm in a chimpanzee. Sci Rep 3:1566. CrossRef Medline

Helmuth LL, Mayr U, Daum I (2000) Sequence learning in Parkinson's disease: a comparison of spatial-attention and number-response sequences. Neuropsychologia 38:1443-1451. CrossRef Medline

Howe MW, Atallah HE, McCool A, Gibson DJ, Graybiel AM (2011) Habit learning is associated with major shifts in frequencies of oscillatory activity and synchronized spike firing in striatum. Proc Natl Acad Sci U S A 108:16801-16806. CrossRef Medline

Iversen JR, Repp BH, Patel AD (2009) Top-down control of rhythm perception modulates early auditory responses. Ann N Y Acad Sci 1169:58-73. CrossRef Medline

Jin DZ, Fujii N, Graybiel AM (2009) Neural representation of time in cortico-basal ganglia circuits. Proc Natl Acad Sci U S A 106:19156-19161. CrossRef Medline

Johnson RA, Wichern DW (1998) Applied multivariate statistical analysis, Ed 4. Englewood Cliffs, NJ: Prentice Hall.

Kalenscher T, Lansink CS, Lankelma JV, Pennartz CM (2010) Rewardassociated gamma oscillations in ventral striatum are regionally differentiated and modulate local firing activity. J Neurophysiol 103:1658-1672. CrossRef Medline

Kay LM, Beshel J (2010) A beta oscillation network in the rat olfactory system during a 2-alternative choice odor discrimination task. J Neurophysiol 104:829-839. CrossRef Medline

Kermadi I, Joseph JP (1995) Activity in the caudate nucleus of monkey during spatial sequencing. J Neurophysiol 74:911-933. Medline

Kopell N, Ermentrout GB, Whittington MA, Traub RD (2000) Gamma rhythms and beta rhythms have different synchronization properties. Proc Natl Acad Sci U S A 97:1867-1872. CrossRef Medline

Kühn AA, Kempf F, Brücke C, Gaynor Doyle L, Martinez-Torres I, Pogosyan A, Trottenberg T, Kupsch A, Schneider GH, Hariz MI, Vandenberghe W, Nuttin B, Brown P (2008) High-frequency stimulation of the subthalamic nucleus suppresses oscillatory beta activity in patients with Parkinson's disease in parallel with improvement in motor performance. J Neurosci 28:6165-6173. CrossRef Medline

Kuri-Morales A (2004) Automatic clustering with self-organizing maps and genetic algorithms: II. An improved approach. WSEAS Trans Syst 2:551556.

Lashgari R, Li X, Chen Y, Kremkow J, Bereshpolova Y, Swadlow HA, Alonso JM (2012) Response properties of local field potentials and neighboring single neurons in awake primary visual cortex. J Neurosci 32:1139611413. CrossRef Medline

Lehéricy S, Ducros M, Van de Moortele PF, Francois C, Thivard L, Poupon C, Swindale N, Ugurbil K, Kim DS (2004) Diffusion tensor fiber tracking shows distinct corticostriatal circuits in humans. Ann Neurol 55:522-529. CrossRef Medline

Leventhal DK, Gage GJ, Schmidt R, Pettibone JR, Case AC, Berke JD (2012) Basal ganglia beta oscillations accompany cue utilization. Neuron 73:523536. CrossRef Medline

Levy R, Ashby P, Hutchison WD, Lang AE, Lozano AM, Dostrovsky JO (2002) Dependence of subthalamic nucleus oscillations on movement and dopamine in Parkinson's disease. Brain 125:1196-1209. CrossRef Medline

Liu J, Newsome WT (2006) Local field potential in cortical area MT: stimulus tuning and behavioral correlations. J Neurosci 26:7779-7790. CrossRef Medline

Macar F, Coull J, Vidal F (2006) The supplementary motor area in motor and perceptual time processing: fMRI studies. Cogn Process 7:89-94. CrossRef Medline

Matell MS, Meck WH (2004) Cortico-striatal circuits and interval timing: coincidence detection of oscillatory processes. Cogn Brain Res 21:139170. CrossRef Medline

Meck WH (2006) Neuroanatomical localization of an internal clock: a func- tional link between mesolimbic, nigrostriatal, and mesocortical dopaminergic systems. Brain Res 1109:93-107. CrossRef Medline

Meck WH, Penney TB, Pouthas V (2008) Cortico-striatal representation of time in animals and humans. Curr Opin Neurobiol 18:145-152. CrossRef Medline

Mehring C, Rickert J, Vaadia E, Cardosa de Oliveira S, Aertsen A, Rotter S (2003) Inference of hand movements from local field potentials in monkey motor cortex. Nat Neurosci 6:1253-1254. CrossRef Medline

Merchant H, Honing H (2014) Are non-human primates capable of rhythmic entrainment? Evidence for the gradual audiomotor evolution hypothesis. Front Neurosci 7:274. Medline

Merchant H, Zainos A, Hernández A, Salinas E, Romo R (1997) Functional properties of primate putamen neurons during the categorization of tactile stimuli. J Neurophysiol 77:1132-1154. Medline

Merchant H, Battaglia-Mayer A, Georgopoulos AP (2001) Effects of optic flow in motor cortex and area 7a. J Neurophysiol 86:1937-1954. Medline

Merchant H, Luciana M, Hooper C, Majestic S, Tuite P (2008a) Interval timing and Parkinson's disease: heterogeneity in temporal performance. Exp Brain Res 184:233-248. Medline

Merchant H, Zarco W, Bartolo R, Prado L (2008b) The context of temporal processing is represented in the multidimensional relationships between timing tasks. PLoS One 3:e3169. CrossRef Medline

Merchant H, Zarco W, Prado L (2008c) Do we have a common mechanism for measuring time in the hundreds of millisecond range? Evidence from multiple-interval timing tasks. J Neurophysiol 99:939-949. CrossRef Medline

Merchant H, Zarco W, Pérez O, Prado L, Bartolo R (2011) Measuring time with different neural chronometers during a synchronizationcontinuation task. Proc Natl Acad Sci U S A 108:19784-19789. CrossRef Medline

Merchant H, de Lafuente V, Peña-Ortega F, Larriva-Sahd J (2012) Functional impact of interneuronal inhibition in the cerebral cortex of behaving animals. Prog Neurobiol 99:163-178. CrossRef Medline

Merchant H, Harrington DL, Meck WH (2013a) Neural basis of the perception and estimation of time. Annu Rev Neurosci 36:313-336. CrossRef Medline

Merchant H, Pérez O, Zarco W, Gámez J (2013b) Interval tuning in the primate medial premotor cortex as a general timing mechanism. J Neurosci 33:9082-9096. CrossRef Medline

Middleton FA, Strick PL (2000) Basal ganglia output and cognition: evidence from anatomical, behavioral, and clinical studies. Brain Cogn 42: 183-200. CrossRef Medline

Mita A, Mushiake H, Shima K, Matsuzaka Y, Tanji J (2009) Interval time coding by neurons in the presupplementary and supplementary motor areas. Nat Neurosci 12:502-507. CrossRef Medline

Mitra PP, Bokil H (2008) Observed brain dynamics. New York: Oxford UP.

Miyachi S, Hikosaka O, Miyashita K, Kárádi Z, Rand MK (1997) Differential roles of monkey striatum in learning of sequential hand movement. Exp Brain Res 115:1-5. CrossRef Medline

Murthy VN, Fetz EE (1996) Synchronization of neurons during local field potential oscillations in sensorimotor cortex of awake monkeys. J Neurophysiol 76:3968-3982. Medline

Mushiake H, Strick PL (1995) Pallidal neuron activity during sequential arm movements. J Neurophysiol 74:2754-2758. Medline

Nagarajan SS, Blake DT, Wright BA, Byl N, Merzenich MM (1998) Practicerelated improvements in somatosensory interval discrimination are temporally specific but generalize across skin location, hemisphere, and modality. J Neurosci 18:1559-1570. Medline

Paninski L, Fellows MR, Hatsopoulos NG, Donoghue JP (2004) Spatiotemporal tuning of motor cortical neurons for hand position and velocity. J Neurophysiol 91:515-532. Medline

Parent A, Hazrati LN (1995) Functional anatomy of the basal ganglia: I. The cortico-basal ganglia-thalamo-cortical loop. Brain Res Rev 20:91-127. CrossRef Medline

Perez O, Kass RE, Merchant H (2013) Trial time warping to discriminate stimulus-related from movement-related neural activity. J Neurosci Methods 212:203-210. CrossRef Medline

Rao SM, Harrington DL, Haaland KY, Bobholz JA, Cox RW, Binder JR (1997) Distributed neural systems underlying the timing of movements. J Neurosci 17:5528-5535. Medline

Repp BH, Su YH (2013) Sensorimotor synchronization: a review of recent research (2006-2012). Psychon Bull Rev 20:403-452. CrossRef Medline 
Sanes JN, Donoghue JP (1993) Oscillations in local field potentials of the primate motor cortex during voluntary movement. Proc Natl Acad Sci U S A 90:4470-4474. CrossRef Medline

Schalk G, Kubánek J, Miller KJ, Anderson NR, Leuthardt EC, Ojemann JG, Limbrick D, Moran D, Gerhardt LA, Wolpaw JR (2007) Decoding twodimensional movement trajectories using electrocorticographic signals in humans. J Neural Eng 4:264-275. CrossRef Medline

Schoffelen JM, Oostenveld R, Fries P (2005) Neuronal coherence as a mechanism of effective corticospinal interaction. Science 308:111-113. CrossRef Medline

Tanji J, Shima K (1994) Role for supplementary motor area cells in planning several movements ahead. Nature 371:413-416. CrossRef Medline

Thomson DJ (1982) Spectrum estimation and harmonic analysis. Proc IEEE 70:1055-1096. CrossRef

Treisman M, Cook N, Naish PLN, MacCrone JK (1994) The internal clock: electroencephalographic evidence for oscillatory processes underlying time perception. Q J Exp Psychol A 47:241-289. CrossRef Medline

Uhlhaas PJ, Pipa G, Lima B, Melloni L, Neuenschwander S, Nikolić D, Singer W, Nikolic D, Lin S (2009) Neural synchrony in cortical networks: history, concept and current status. Front Integr Neurosci 3:17. CrossRef Medline

Waldert S, Preissl H, Demandt E, Braun C, Birbaumer N, Aertsen A, Mehring
C (2008) Hand movement direction decoded from MEG and EEG. J Neurosci 28:1000-1008. CrossRef Medline

Weinberger M, Hutchison WD, Dostrovsky JO (2009) Pathological subthalamic nucleus oscillations in PD: can they be the cause of bradykinesia and akinesia? Exp Neurol 219:58-61. CrossRef Medline

Wiener M, Turkeltaub P, Coslett HB (2010) The image of time: a voxel-wise meta-analysis. Neuroimage 49:1728-1740. CrossRef Medline

Wing AM, Kristofferson AB (1973) Response delays and the timing of discrete motor responses. Percept Psychophys 14:5-12. CrossRef

Witham CL, Baker SN (2012) Coding of digit displacement by cell spiking and network oscillations in the monkey sensorimotor cortex. J Neurophysiol 108:3342-3352. CrossRef Medline

Wright BA, Buonomano DV, Mahncke HW, Merzenich MM (1997) Learning and generalization of auditory temporal-interval discrimination in humans. J Neurosci 17:3956-3963. Medline

Zarco W, Merchant H, Prado L, Mendez JC (2009) Subsecond timing in primates: comparison of interval production between human subjects and rhesus monkeys. J Neurophysiol 102:3191-3202. CrossRef Medline

Zhuang J, Truccolo W, Vargas-Irwin C, Donoghue JP (2010) Decoding 3-D reach and grasp kinematics from high-frequency local field potentials in primate primary motor cortex. IEEE Trans Biomed Eng 57:1774-1784. CrossRef Medline 